\title{
An Observational Analysis Quantifying the Distance of Supercell-Boundary Interactions in the Great Plains
}

\author{
KATHLEEN M. MAGEE \\ National Weather Service Huntsville, Huntsville, AL \\ CASEY E. DAVENPORT \\ University of North Carolina at Charlotte, Charlotte, NC
}

(Manuscript received 11 June 2019; review completed 7 October 2019)

\begin{abstract}
Several case studies and numerical simulations have hypothesized that baroclinic boundaries provide enhanced horizontal and vertical vorticity, wind shear, helicity, and moisture that induce stronger updrafts, higher reflectivity, and stronger low-level rotation in supercells. However, the distance at which a surface boundary will provide such enhancement is less well-defined. Previous studies have identified enhancement at distances ranging from $10 \mathrm{~km}$ to $200 \mathrm{~km}$, and only focused on tornado production and intensity, rather than all forms of severe weather. To better aid short-term forecasts, the observed distances at which supercells produce severe weather in proximity to a boundary needs to be assessed.

In this study, the distance between a large number of observed supercells and nearby surface boundaries (including warm fronts, stationary fronts, and outflow boundaries) is measured throughout the lifetime of each storm; the distance at which associated reports of large hail and tornadoes occur is also collected. Statistical analyses assess the sensitivity of report distributions to report type, boundary type, boundary strength, angle of interaction, and direction of storm motion relative to the boundary. Additionally, the range at which each type of severe weather is produced for each boundary is identified to provide a useful operational tool for forecasters. Notably, tornadoes are more likely to be produced closer to a boundary than severe hail. Overall, the observations point to a unique range at which severe weather occurs for each boundary and report type.
\end{abstract}

\section{Introduction and motivation}

\section{a. Motivating case studies}

It is well established that storms are more likely to become supercells and produce severe weather near a surface boundary (e.g., Maddox et al. 1980; Markowski et al. 1998b; Rasmussen et al. 2000; Bunkers et al. 2006b; Houston and Wilhelmson 2012). One such example occurred on 25 May 2016, where the 1300 UTC Day 1 Outlook issued by the Storm Prediction Center (SPC) indicated a marginal risk area over the eastern half of the Great Plains, citing that there will be "little forcing for ascent" in the region. Subsequent updates to the Day 1 Outlook at 1630 and 2000 UTC both acknowledge the unstable air mass over eastern Kansas with analyzed surface-based convective available potential energy (SBCAPE) values between 5000 and $6000 \mathrm{~J} / \mathrm{kg}$, yet only indicate the possibility for an isolated, brief tornado, due to the lack of vertical wind shear in the environment. The SPC Severe Weather Event Archive (SWEA) for the event confirms a lack of environmental vertical wind shear throughout the event, indicating that in order for tornadogenesis to occur, a separate source of wind shear is required. The short-term forecast rapidly changed due to a remnant outflow boundary over northeastern Kansas (Fig. 1a). Over the next several hours, the outflow boundary moved southward, until the environmental warm air began to spread into the cooler air, causing the boundary to retreat northward (Fig. 1b, c). Because the warmer air was surging into the cooler air from the previous convective activity, 


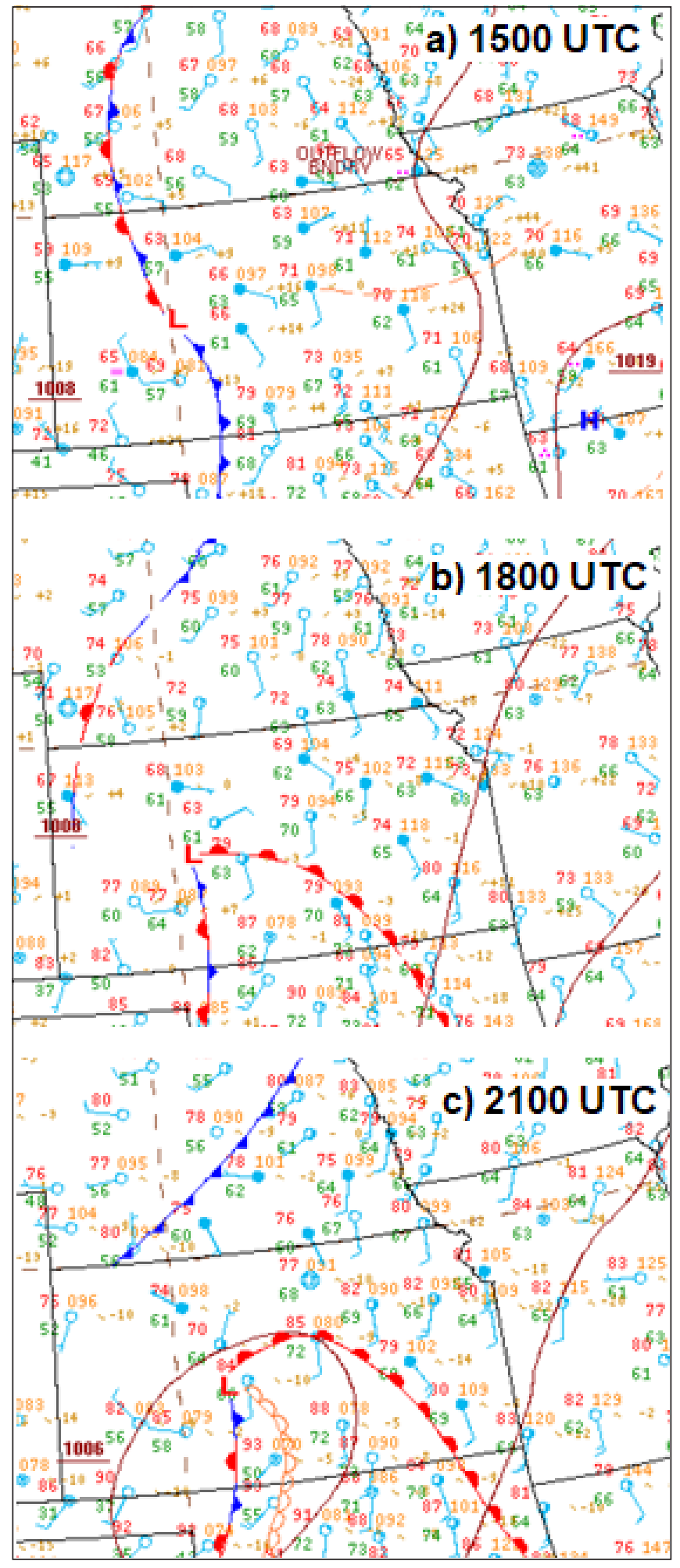

Figure 1. WPC surface analysis from 25 May 2016. Click image for an external version; this applies to all figures and hereafter. this was analyzed as a warm front. An isolated storm initiated at 2200 UTC in the vicinity of the warm front and rapidly developed into a supercell.

At 2308 UTC, when the isolated supercell was south of Minneapolis, Kansas, it produced its first tornado-an EF0 with a 0.47-mile path length. This supercell continued to produce four additional tornadoes, including an EF4 tornado with a 42-km path length, which was on the ground for 90 minutes. The Chapman, Kansas supercell initially became tornadic approximately $22 \mathrm{~km}$ from the warm front in the cool sector. The EF4 Chapman, Kansas tornado formed at $2320 \mathrm{UTC}$, at which point our analyses place the supercell approximately $20 \mathrm{~km}$ in the cool sector. The proximity of this isolated supercell to the boundary is one potential explanation for why a violent tornado formed that day.

The 25 May 2016 event illustrates some consistencies with previous studies on supercellboundary interaction; notably, tornadoes tend to occur in close proximity to boundaries (e.g., Markowski et al. 1998a), though the degree of closeness can vary. On 9 April 2011, a warm front passed over central Iowa around 2300 UTC, with an isolated supercell forming just on the warm side of the boundary. The supercell quickly produced 1.75 in hail at 2317 UTC and became tornadic at 2320 UTC with an EF3 tornado, approximately 10 $\mathrm{km}$ from the boundary in the warm sector. Whereas the initial time of tornadogenesis is when the supercell is in close proximity to the boundary, the supercell remains tornadic (and at times significantly tornadic, $\geq E F 2$ ) until $0318 \mathrm{UTC}$ when it is over $60 \mathrm{~km}$ in the warm sector. Severe hail, at times up to 2.00 inches in diameter, also was produced up to $68 \mathrm{~km}$ away from the boundary in the warm sector, begging the question as to whether or not the presence of the warm front nearby played a role. Such a connection between boundary proximity and enhancement of other types of severe weather (i.e., strong winds and large hail) is currently unknown.

\section{b. Previous literature}

\section{1) Boundary structure}

A boundary is defined as the separation between two air masses: generally, one warm and moist and another cooler and drier. Because of this difference in air mass, cross sections of the warm sector, cool sector, and directly on the boundary will yield distinctly different atmospheric profiles (e.g., Maddox et al. 1980; Fig. 2). 


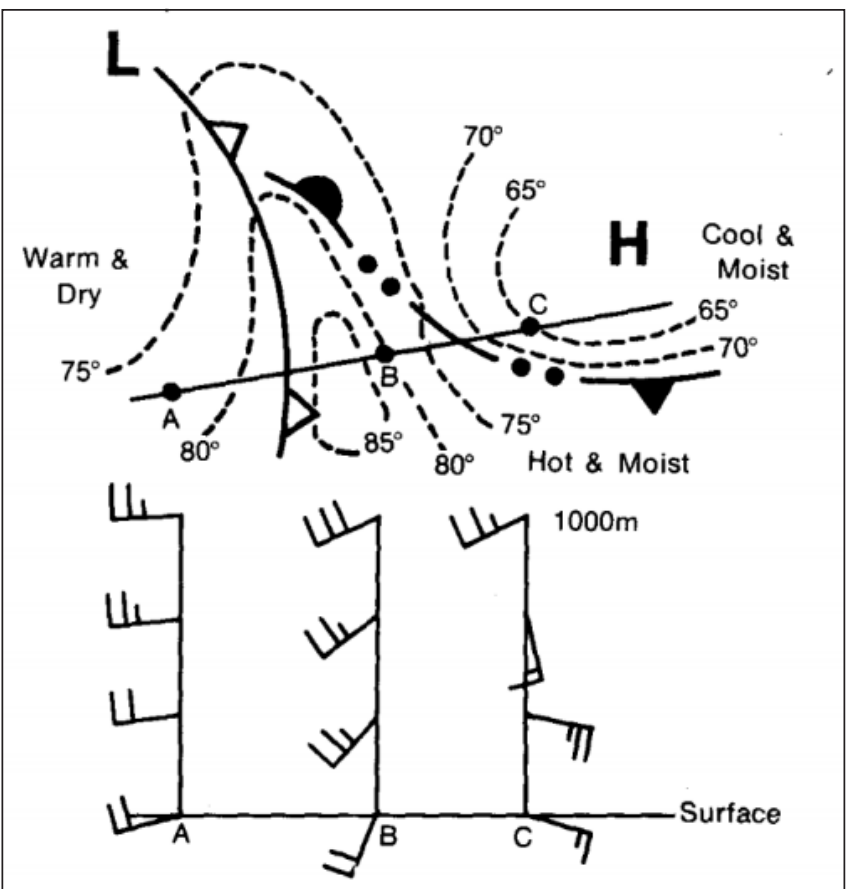

Figure 2. Cross section through two boundaries illustrating representative wind profiles for a wellmixed warm and dry air mass (profile A); a hot and moist, conditionally unstable air mass (profile B); and a cool and moist air mass behind an outflow boundary (profile C). Figure taken from Maddox et al. (1980).

In particular, the varying wind profiles act to maximize meso- $\beta$ moisture convergence and vertical cyclonic vorticity, referred to as the "mesoscale intensification effect". In turn, this local enhancement of vertical vorticity and moisture convergence can compensate for less-than-favorable synoptic conditions, which can enhance the likelihood of tornadogenesis (e.g., Wakimoto et al. 1998; Rasmussen et al. 2000; Boustead et al. 2013). The enhanced moisture convergence along a boundary creates a mixing zone on the immediate warm side of the boundary, which is then prone to smaller-scale cyclonic circulations (Maddox et al. 1980, case study A). Additionally, streamwise horizontal vorticity, as represented by storm-relative helicity (SRH), has been observed to vary drastically over relatively short time and distance scales, on the order of two magnitudes in less than $100 \mathrm{~km}$ or fewer than three hours (Markowski et al. 1998b). Such large shifts can be problematic for severe weather forecasting, especially tornadoes. Limited spatial and temporal sampling of low-level thermodynamic and kinematic fields binds the forecaster's ability to adequately perform mesoanalysis and identify areas with more significant severe weather potential. Increasing the spatial resolution of environmental analysis should continue to be a priority for research and field experiments in the vicinity of surface boundaries.

\section{2) Supercell boundary interaction}

The enhancement of SRH, horizontal and vertical vorticity, and moisture along a boundary has been proven to increase the likelihood of severe weather. Indeed, Markowski et al. (1998a) found that the majority (70\%) of the tornadoes studied during the original Verification of the Origins of Rotation in Tornadoes Experiment (VORTEX, Rasmussen et al. 1994) occurred near boundaries, tied to the tilting of enhanced horizontal vorticity (Fig. 3). Additional studies have further demonstrated that tornadic supercells traveling along or just into the cool sector of a boundary benefit from the favorable environment with a stronger mesocyclone and are more likely to undergo tornadogenesis (Rasmussen et al. 2000; Gilmore and Wicker 2002; Fierro et al. 2006).

The angle of storm motion relative to the boundary is another important consideration for promoting

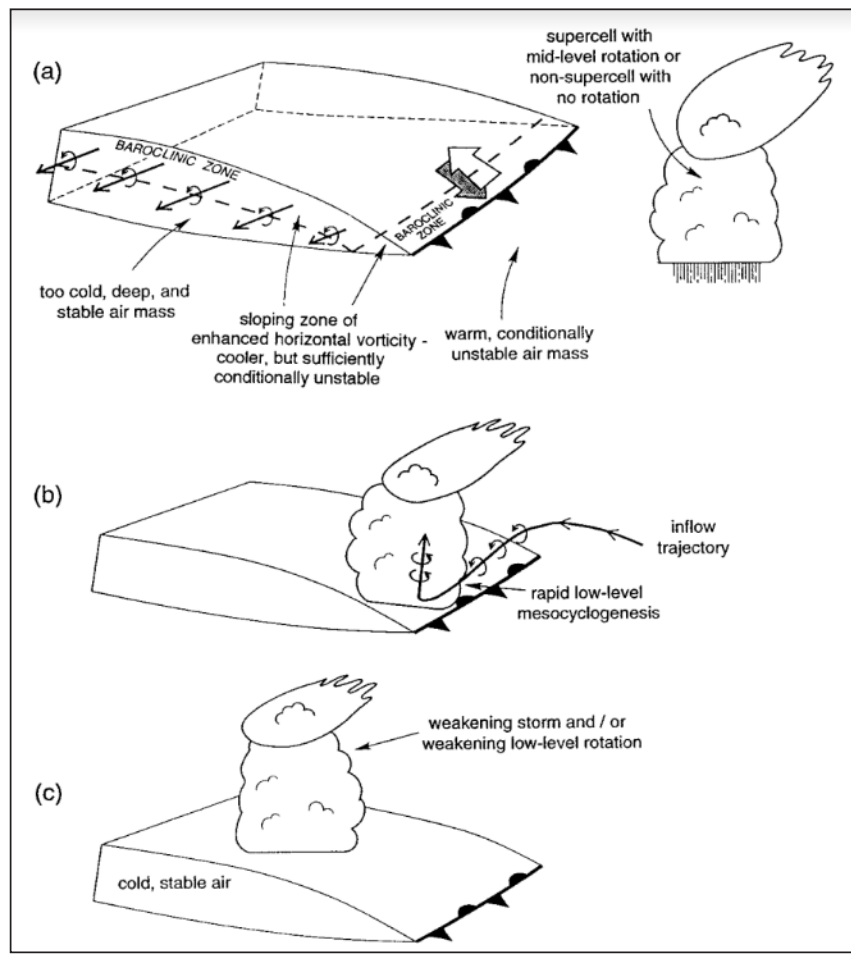

Figure 3. Conceptual model of horizontal vorticity along a baroclinic zone impacting the development of low-level rotation in a supercell. Figure from Markowski et al. (1998a). 
a favorable supercell-boundary interaction. Both observational studies (Rasmussen et al. 2000; Bunkers et al. 2006b) and numerical simulations (Atkins et al. 1999; Laflin and Houston 2012) concluded that supercells moving parallel to boundaries contained more intense and longer-lasting mesocyclones. The more time a supercell spends near a boundary, the longer it may benefit from the favorable environment, therefore leading to a longer supercell lifetime (Bunkers et al. 2006a). This effect was clearly demonstrated in Atkins et al. (1999), in which the simulated right-mover from a splitting supercell traveled quickly across the boundary and exhibited weaker vorticity and a weaker updraft. In contrast, the supercells that moved along the boundary developed significant low-level rotation quicker than those that crossed the boundary.

Atkins et al. (1999) further examined the extent to which the strength of the boundary's temperature gradient influenced supercell intensity, as a stronger temperature gradient would lead to more baroclinically generated horizontal vorticity. Notably, their experiments demonstrated that the gradient strength had no impact on the strength or evolution of the lowlevel mesocyclone. This finding was observationally supported by Weiss et al. (2015), which examined two supercells: one with weakly tornadic and non-tornadic phases along a strong temperature gradient, and another with a strongly tornadic phase along a weaker temperature gradient. The contrast between the two supercells highlights the importance of the supercellboundary angle; the strongly tornadic supercell traveled parallel to the boundary, whereas the weakly/nontornadic supercell's motion was oriented perpendicular to the boundary. It is unclear whether the interaction angle or the temperature gradient played the stronger role in the observed evolution of the storms, and a larger observational sample would assist in this conclusion.

\section{3) Quantifying distances in previous research}

Previous studies have quantified "boundary influence" based on a variety of distances between supercells and a nearby boundary. These span a broad range, starting as low as $10 \mathrm{~km}$ (specifically promoting tornadogenesis; Markowski et al. 1998a), to 35-40 km (enhancement of low-level mesocyclones; Gilmore and Wicker 2002, Fierro et al. 2006, respectively), to 60 $\mathrm{km}$ (Rasmussen et al. 2000), all the way up to $200 \mathrm{~km}$ (Gagne II et al. 2012). The $200 \mathrm{~km}$ distance is arguably too far for supercells to be reasonably considered enhanced by a boundary, as such a distance would mean that any supercell within the warm or cool sector of a warm front would be enhanced (e.g., Bunkers et al. 2006b). A much larger dataset is needed to verify any of the suggested thresholds from previous research.

Overall, it is unclear at what range forecasters can expect a supercell to be enhanced by a nearby boundary and what the sensible impacts of that enhancement might be. Markowski et al. (1998a) defined a clear range for tornadoes, but it is unknown if these distances can be extended to other types of severe weather, namely hail and wind. Additionally, although it appears that boundary strength is not a distinguishing factor (Atkins et al. 1999; Weiss et al. 2015), it is unknown whether boundary type (e.g., warm front versus stationary front) or depth (outflow boundary versus warm or stationary fronts) plays a role in producing varying degrees of enhancement. This study will quantify the distances between observed supercells and nearby surface boundaries and correlate them to production of severe weather with the broader goal of assisting forecasters in mesoanalysis to support short-term predictions.

\section{Data and methods}

To address the goal of this study, 90 isolated supercells located near boundaries were identified and then tracked throughout their lifetime, along with their associated severe reports (including hail, wind, and tornadoes). We focus here on supercell interactions with outflow boundaries, stationary fronts, and warm fronts. A warm front is defined as an air mass of warmer air advancing on an air mass of cooler air over an extended period of time. The second boundary type studied is a stationary front, which may occasionally oscillate into one air mass or another but does not make great progress into one direction over an extended period of time. The third boundary analyzed in this study is an outflow boundary, which is an air mass produced by and traveling radially outward from a thunderstorm; typically, this air mass is characterized by cooler, more dense air rushing into warmer, less dense environmental air. With the complicating factor of nocturnal transitions in mind, an outflow boundary is defined in this study as an air mass from a thunderstorm progressing away from the parent thunderstorm and into environmental air.

In the case of the 25 May 2016 Chapman, Kansas tornado, an outflow boundary was present in the vicinity of where the supercell, and resultant tornado, would eventually form. It is also noted that 
beginning at $1800 \mathrm{UTC}$, the remnant boundary began to progress northward, indicating that the warmer environmental air was surging to the north into the air mass resulting from convection over eastern Nebraska the previous evening. Because it was the warmer, moister air surging into the cooler air mass, this study has chosen to define the boundary as a warm front. It is worth noting that the Chapman, Kansas tornado case study highlights discrepancies in frontal boundary definitions, which deserves stronger clarification in the meteorological community. Proper analysis skill, particularly as it relates to severe weather, is crucial within the operational forecasting community, as any inconsistencies in analysis between offices may result in severe discrepancies in the forecast. Drylines were excluded from this study because of supercells' tendency to develop along the dryline and then move away, preventing any further interaction. Additionally, supercell interaction with cold fronts is not examined, as the cold fronts often undercut supercells too quickly, thus inhibiting any prolonged interaction.

To provide a sufficient dataset for statistical comparisons, we strove to identify 30 supercell cases for each boundary type. Cases were selected between 2005 and 2016 between the months of March and June (Fig. 4), when supercells are most frequent, and in the Great Plains, as defined from the Mississippi River Basin to the Rocky Mountains.

\section{a. Data sources}

Cases were chosen from the SPC Severe Weather Events Archive (SWEA) by identifying days where severe storm reports were present in the Great Plains. Once a severe weather day was found in the SWEA, the Weather Prediction Center (WPC) surface analysis archive was used as a first guess to investigate whether one of the desired boundaries was present in the broad vicinity of the reports. The surface analysis primarily helped to locate stationary and warm fronts, as well as more prominent outflow boundaries. For smaller, more mesoscale outflow boundaries, the National Centers for Environmental Information (NCEI) Radar Data page, which shows archived Level 2 data, was used to see if an outflow boundary was resolved by a radar. All archived mesoscale analysis data in the SPC SWEA was utilized for each individual case to confirm the boundary analysis done by WPC. If a boundary was not identifiable by a fine line on radar or any archived mesoanalysis product, then the case was eliminated from potential analysis.

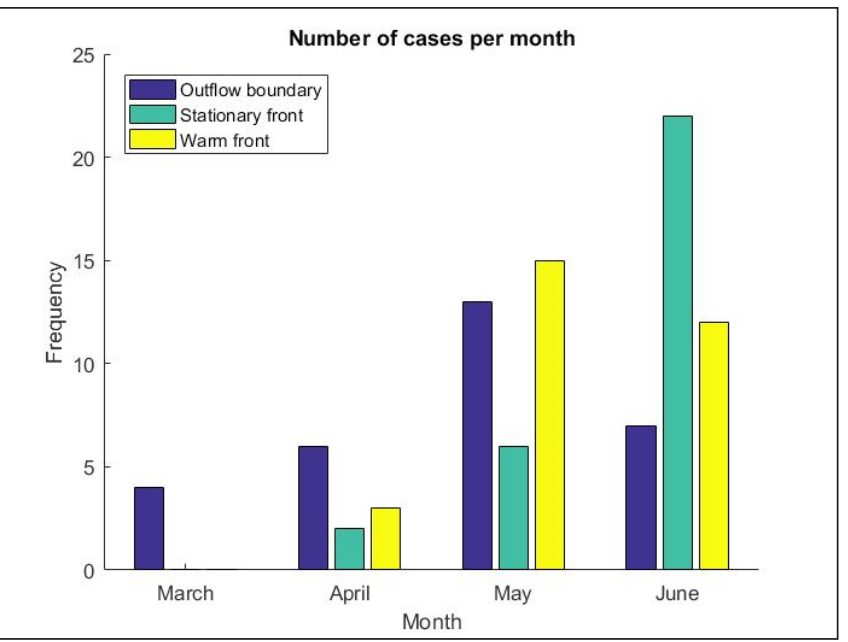

Figure 4. Distribution of total number of cases per month for outflow boundary cases (blue), stationary front cases (green), and warm front cases (yellow).

After the initial query from SPC SWEA, there were 38 outflow boundary cases, 46 stationary front cases, and 36 warm front cases identified.

Following selection of a case based on proximity to a boundary and production of severe weather, individual storms were further examined to verify they were supercells via the Mesocyclone Detection Algorithm (MDA) in archived radar data, with any of the vortex classifications considered satisfactory to define a mesocyclone presence (Stumpf et al. 1998). Level 2 radar data also was collected for verified supercells to identify low-level rotation throughout the storm's lifetime with rotational velocity values of at least $20 \mathrm{~ms}^{-1}$. Note that if more than one supercell were present near the boundary of interest, each supercell was counted as its own individual case, but care was taken to ensure that each supercell was isolated. After this analysis, the total number of cases was reduced to 35 outflow boundary cases, 41 stationary front cases, and 32 warm front cases.

It is acknowledged that the use of the SPC storm reports for this study is not without its limitations and biases. There are many well-documented issues with publicly generated reports, including a nonmeteorological increase in the number of reports over time (Weiss et al. 2002), overestimated wind speeds by human observers (Doswell et al. 2005; Edwards 2018), and a bias of higher severe reports near areas with a higher population density (Trapp et al. 2006). The National Weather Service's (NWS) Storm Events Database was used to confirm reports collected from SPC archives, as well as to include EF-scale intensity. 
Finally, it is noted that filtered storm reports were used for cases after 2011; for cases prior to 2012, reports were filtered by hand. If there were reports from the same time with locations within 0.01 coordinate degree of one another, and were the same quantity (e.g., same hail size or wind speed), then this group of reports was "filtered" down into a single representative report. It should be noted that this filtering technique is different from the one utilized by SPC.

The position of each identified boundary by WPC analyses was used as a first guess, as the data are only available every three hours. Boundary placement was then altered based on nearby surface observations from the Surface Airways Observations (SAO) data, available every 20 minutes; the 20 -min window thus represents the frequency at which our storm distance analyses will be conducted, discussed in more detail in the next subsection. When available, a local mesonet and archived satellite imagery were used to increase confidence and spatial resolution of boundary placement. It should be noted that there were two warm front cases where the authors identified the boundary in a different location than the official WPC analysis.

Limitations in availability of radar and surface observation networks reduced the total number of cases at this point to 30 outflow boundary cases, 35 stationary front cases, and 30 warm front cases. As 30 was the lowest common number, each case within the stationary front cases were randomly assigned a number ranging from 1 to 35, and then a random number generator was used to list numbers from 1 to 35 . The first 30 numbers listed were the 30 cases utilized from the repository of stationary front cases, thus bringing the total number of cases analyzed in this study to 90: 30 outflow boundary, 30 stationary front, and 30 warm front cases.

\section{b. IDV analysis}

To quantify the distance between each supercell and the nearby boundary, the drawing tool in the Integrated Data Viewer (IDV) from UCAR/Unidata was utilized by overlaying radar data and surface data. Every 20 min, a straight line was drawn from the tip of the hook echo to the boundary; if no hook echo was present, then the distance was measured from the storm centroid to the boundary. This measurement was collected between storm initiation and storm dissipation, or transition into a mesoscale convective system (MCS).

To correlate individual (filtered) severe weather reports with their corresponding supercell, the recorded coordinates of the severe report were compared to the placement of the supercell using a radar image from the same time as the report. If the severe report location aligned with the supercell location, the time and size (hail), speed (wind), or EF scale (tornado, via the Storm Event Database) was recorded. Next, to determine the distance at which the report occurred, the recorded time in the SPC SWEA is linearly interpolated from the 20-min interval recorded distances. For example, if a report occurred at 2014 UTC, the distances recorded at 2000 and 2020 UTC are linearly interpolated to find the distance of the supercell from the boundary at 2014 UTC.

Notably, the described approach of measuring storm distance from the boundary may be subject to error. A small shift of a few millimeters on the computer screen may result in an error as large as $10 \mathrm{~km}$, which would alter the interpolated distances of the severe reports. Additionally, the analyzed location of the surface boundaries between WPC analyses was largely dependent on the density of surface weather stations. If there were sparse reports at the time of analysis, the location of the boundary may also be off by several kilometers. Density of the surface observation network was not used as a method to eliminate cases from the study. To quantify the amount of subjectivity present in this study, a second analysis was conducted by a third-party researcher on one randomly chosen case per boundary type. The average difference in analyzed distances per boundary type was $10.92 \mathrm{~km}$, consistent with the error in the Markowski et al. (1998a) study; to acknowledge the potential error in our data, a label of $+/-10 \mathrm{~km}$ will be included in relevant figures.

\section{c. Temperature gradient analysis}

To assess the influence of boundary strength on severe weather production, the temperature gradient at the time of severe weather reports also was collected. NWS Automated Surface Observational System (ASOS) and Remote Automated Weather Stations (RAWS) observations were utilized to determine the temperature difference across the boundary. The representative sites were chosen in the warm and cool sectors so that the data points chosen were representative of their respective air masses, which is not always sufficiently portrayed by the data from the stations closest to the boundary. As the boundary progressed, different stations were used for comparisons so that the most representative data were used for the calculation 
of boundary strength. The temperature difference was then divided by the distance between the two site locations to calculate the temperature gradient every $20 \mathrm{~min}$ to $60 \mathrm{~min}$, depending on data availability from the weather station. The average distance between the two weather stations used to calculate temperature gradient was $190.3 \mathrm{~km}$. A distance this large also may be subject to meso- or microscale changes in the temperature gradient that is undetectable by surface observation networks. Using the same technique as the boundary distance interpolation, the time of the storm report was then linearly interpolated between the two values of temperature gradient, and then that value was classified to the specific boundary and severe weather type associated with the severe weather report.

\section{Results}

\section{a. Diurnal occurrence}

The majority of the 90 cases examined in this study largely occurred during the late afternoon and early evening hours, consistent with previous studies (e.g., Bunkers et al. 2006a). Interestingly, there are differences in temporal frequency depending on boundary type. As illustrated in Fig. 5, outflow boundary-interacting supercells are most frequent near 0400 UTC, while stationary and warm front interacting supercells are most frequent between 2200 and 0100 UTC. The relative delay for outflow boundary cases is likely due to their reliance on the existence of prior convection to have an outflow boundary with which to interact. Notably, the relative delay for supercells that interacted with outflow boundaries indicates that nocturnal cooling likely had a greater effect on the evolution of these storms (including their production of severe weather), less so than the warm front and stationary front cases. Therefore, it is worth noting that outflow cases have fewer overall severe reports compared to both stationary and warm front cases (Table 1).

Because some of the cases were nocturnal, additional analysis was done in the SPC SWEA utilizing effective SRH for cases after 2011 to determine whether or not the effective inflow base (defined by Thompson et al. 2007) was at the surface or elevated, which would imply elevated convection and therefore limited interaction with surface-based boundaries. Although two cases for outflow boundaries did have elevated effective inflow bases, this occurred after the severe weather was produced, but while the supercell was still active. It is

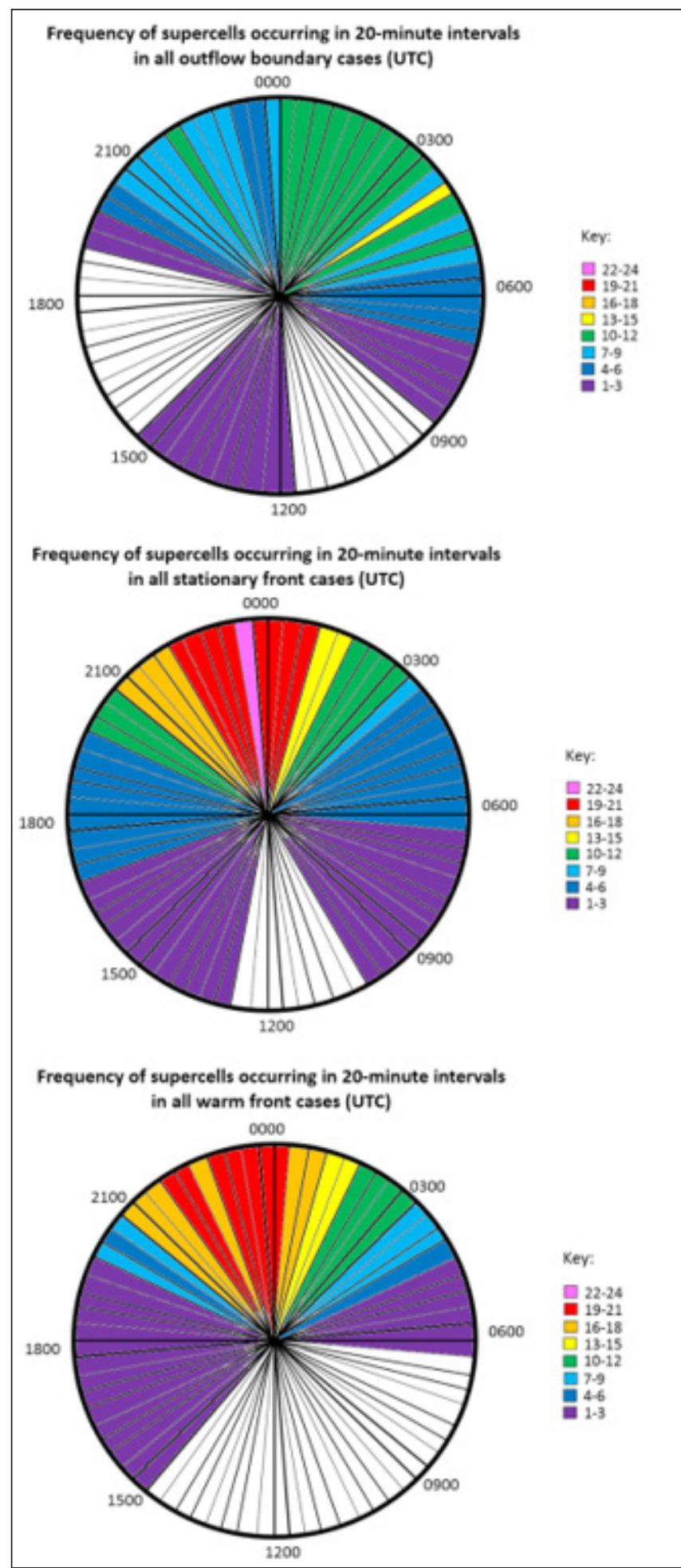

Figure 5. Heat map of the lifetime for all supercells per boundary type, as divided by 20 -min intervals in a $24-\mathrm{h}$ cycle in UTC. 
Table 1. Total number of reports per boundary type used in distributions. Numbers within parenthesis are the total number of significantly severe reports.

\begin{tabular}{|l|l|l|l|l|}
\hline & Tornado & Hail & Wind & Total \\
\hline Outflow & $75(20)$ & $53(10)$ & $29(2)$ & $157(32)$ \\
\hline Stationary & $66(10)$ & $150(49)$ & $59(13)$ & $275(72)$ \\
\hline Warm & $130(32)$ & $123(28)$ & $16(1)$ & $269(61)$ \\
\hline Total & $271(62)$ & $326(87)$ & $104(16)$ & $701(165)$ \\
\hline
\end{tabular}

thus worth noting that if a supercell was elevated after the nocturnal transition, or interacting with an elevated boundary, then there would be a greater margin of error in boundary placement due to the fact that only surface observations were utilized in this study.

\section{b. Supercell-boundary distance}

One of the primary goals of this study was to determine how the distance of a supercell from a surface boundary affects severe weather production. For both outflow boundary cases and stationary front cases, the average distance of a supercell to the interacting boundary lies in the warm sector (Fig. 6), while warm front cases' average distance is nearly on the boundary, although slightly within the warm sector. This result is fairly unsurprising, as supercells tend to spend a majority of their time on the warm side of a boundary due to the abundance of warm, moist air and sufficient instability. However, the supercell location relative to a boundary varies over time. The average boundary distance at the initial development, midpoint, and demise or upscaling of each supercell's lifetime shows clear trends; over time, supercells typically move progressively toward the cool side of the boundary, where enhanced convective inhibition likely contributes to storm demise (Fig. 7).

Examining the overall direction of supercell motion (either toward or away from the boundary) in comparison to production of severe weather also illustrates a clear trend; consistent with prior studies, the frequency of storm reports notably increases the closer the supercell travels to the boundary (Fig. 8; e.g., Maddox et al. 1980; Markowski et al. 1998a). Qualitatively, tornado reports tend to increase just before or after crossing the boundary, implying that the interaction of the supercell with the boundary is what induced tornadogenesis. The proclivity for a majority of storms crossing a boundary to maintain or develop tornadic activity (e.g., Rasmussen et al. 2000), as well as how the frequency of reports increases as several supercells approach the boundary,

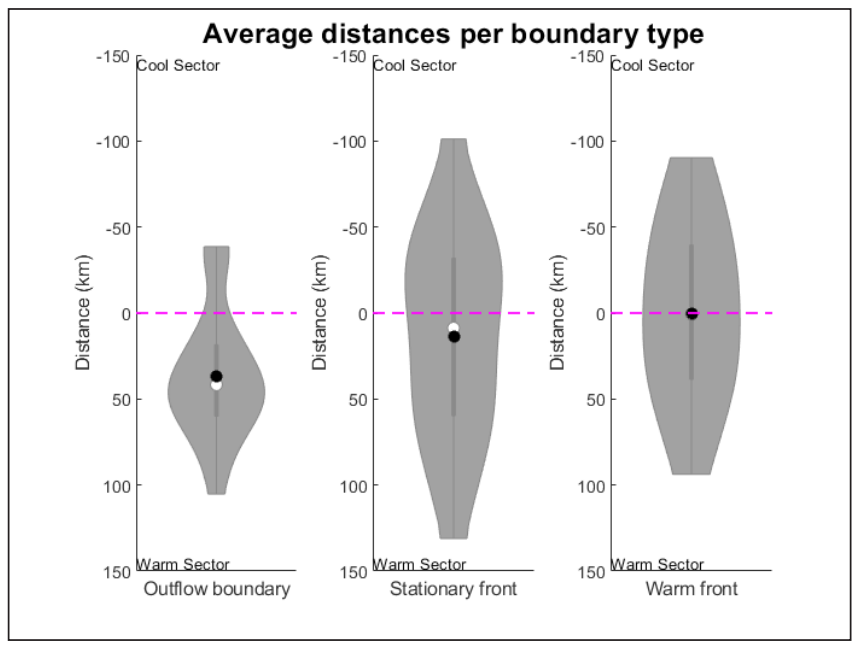

Figure 6. Violin plots of the average distance of all supercells per boundary type throughout the supercell's lifetime with the boundary indicated by the value 0 . Positive distances represent the warm sector and negative values represent the cool sector. Boundary denoted by the magenta dashed line. The central dot marks the median, the thick gray line marks the interquartile range of the 25th and 75th percentiles, and the thin gray line is the range containing $95 \%$ of all data. The edges are a kernel density function of the distribution of data points, thus showing the distribution and frequency of reports rather than a traditional box plot. The black dot denotes the distribution mean. Analyzed distances $+/-10 \mathrm{~km}$.

reinforces the idea that a boundary enhances low-level rotation, potentially contributing to tornadogenesis. Similarly, hail reports tend to increase in frequency the closer a supercell moves to the boundary, suggesting that environmental features such as enhanced SRH or moisture convergence near a boundary lead to a stronger updraft and mesocyclone characteristic of supercells, and thus increase the likelihood of large hail formation (Blair et al. 2017).

To better quantify the distance at which severe reports most commonly occur, we examined the distribution of severe reports (binned by distance from 

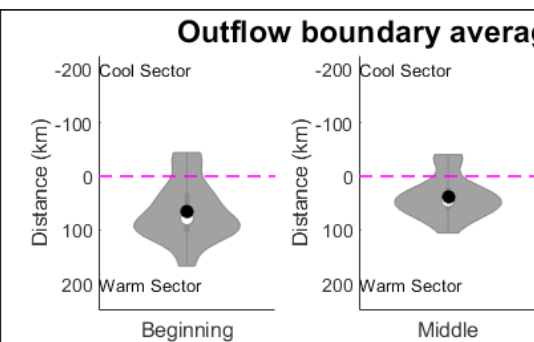

(a)

Stationary front average distances
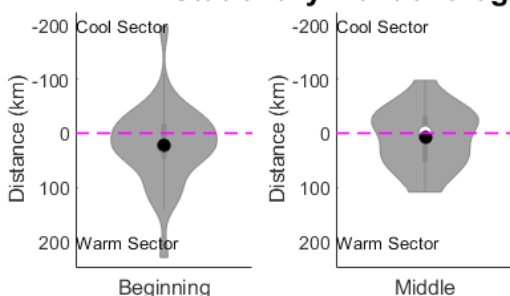

(b)

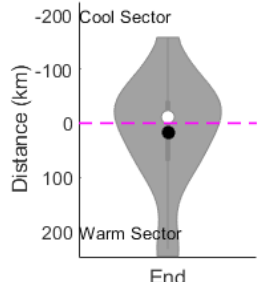

End

Warm front average distances
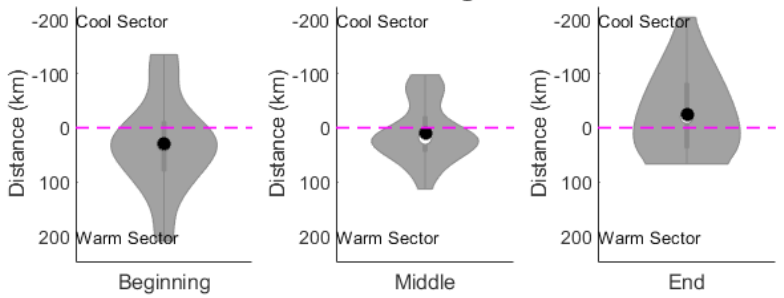

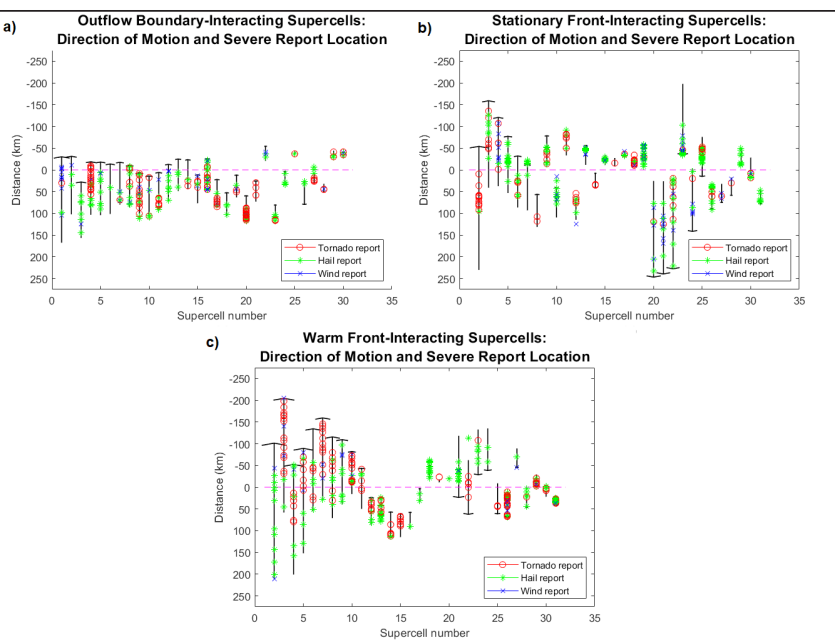

Figure 8. Supercell motion vectors starting at boundary distance at the beginning of the supercell's lifetime and ending at the end of the supercell's lifetime for (a) outflow boundary-interacting supercells, (b) stationary frontinteracting supercells, and (c) warm front-interacting supercells. Negative distances correlate to supercell location in the cool sector. The y-axis represents the distance from the boundary (purple-dashed line) with distances in the warm sector as a positive distance, and distances in the cool sector as a negative distance. The vectors are separated by direction of supercell motion toward warmer or cooler air, and then sorted by total path difference within those two sectors. Vectors that appear very small traveled along the boundary, resulting in a smaller total path difference. These vectors extend from the supercell's starting distance from the boundary to its ending distance. Analyzed distances $+/-10 \mathrm{~km}$.

relationships using various boundary distances as a cutoff point, there was no notable effect on the statistically significant relationships present (described later in the Statistical Analyses section). Thus, this chosen threshold of $70 \mathrm{~km}$ does not significantly influence the overall results of this study.

The mean and median distances for most report distributions are in the warm sector, which is to be expected, as the average distance for all supercells is also in the warm sector. For outflow boundaryinteracting supercells, the mean is lower than the median due to several outlier reports well into the cool sector (Table 2, Fig. 9). Both the median and modes for reports associated with outflow boundaries farther into the warm sector lead to a negative skewness, demonstrating that the histograms are more heavily distributed to the right. Indeed, this is visually confirmed in Fig. 9a where most reports occur in the warm sector 
Table 2. The mean, median, mode, and skewness of all distance distributions. Mode is listed based on the $5 \mathrm{~km}$ bin used to display the data. Skewness is a measure of the asymmetry of the data around the sample mean. If skewness is negative, the data are spread out more to the left of the mean than to the right. If skewness is positive, the data are spread out more to the right. The skewness of the normal distribution (or any perfectly symmetric distribution) is zero.

\begin{tabular}{|l|l|l|l|l|}
\hline & Mean $(\mathbf{k m}):$ & Median $(\mathbf{k m}):$ & Bin mode $(\mathbf{k m}):$ & Skewness: \\
\hline Tornado-outflow & 25.8 & 27.8 & $25-30$ & -0.70 \\
\hline Hail-outflow & 22.6 & 28.1 & $30-35$ & -0.58 \\
\hline Wind-outflow & 14.0 & 17.4 & $40-45$ & -0.41 \\
\hline Tornado-stationary & 0.37 & -13.4 & $60-65$ & 0.21 \\
\hline Hail-stationary & -10.9 & -21.9 & $-25-(-30)$ & 0.76 \\
\hline Wind-stationary & -30.0 & -40.0 & $-50-(-55)$ & 1.68 \\
\hline Tornado-warm & 11.3 & 21.9 & $20-25 ; 30-35 ; 40-45$ & -0.51 \\
\hline Hail-warm & -3.7 & -1.76 & $15-20$ & -0.02 \\
\hline Wind-warm & -9.1 & -23.4 & $-40-(-45)$ & 0.45 \\
\hline
\end{tabular}

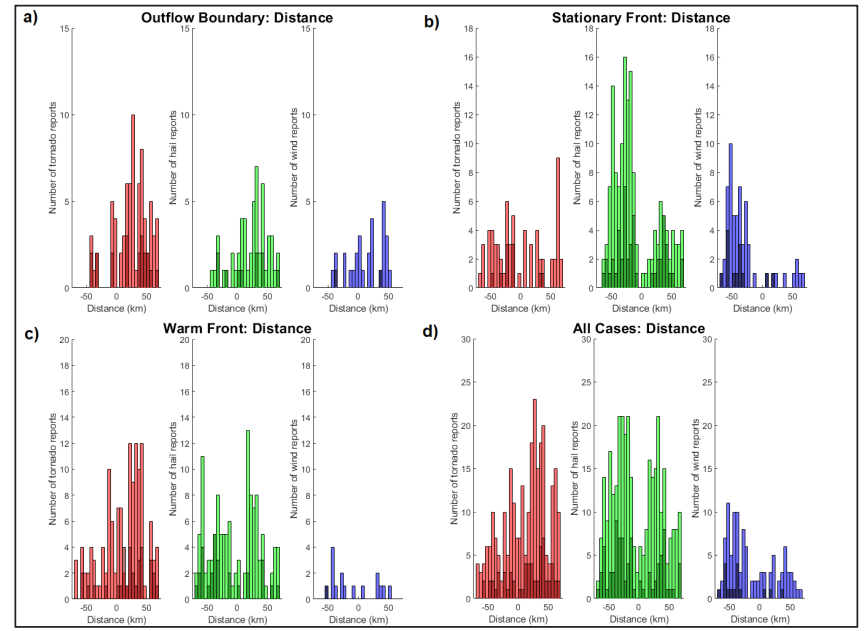

Figure 9. Histograms of distance of severe reports associated with outflow boundaries (a), stationary fronts (b), warm fronts (c), and all reports (d) with $5 \mathrm{~km}$ bins with the significantly severe reports distributions marked in the darker colors. Analyzed distances $+/-10$ $\mathrm{km}$.

for outflow boundary-interacting supercells. Given that most of the outflow-interacting supercells were moving toward the cooler air behind the boundary, the increased frequency of reports occurring in the $30-40 \mathrm{~km}$ range in the warm sector indicates that this is a distance at which supercell enhancement may occur. It should be noted that this enhancement in the warm sector may be a result of a favorable environment in the warm sector, rather than because of the presence of the outflow boundary. That said, Maddox et al. (1980) does suggest that the favorable mixing zone on the warm side of a boundary may explain the proclivity for supercells to become tornadic as they approach the boundary, rather than after crossing the boundary into the cool sector.

Conversely, the distributions of severe reports for stationary boundary-interacting supercells demonstrate that most reports fall in the cool sector (Table 2). Histograms of all report types produced near stationary boundaries effectively portray two distinct modes for severe weather production: one in the warm sector, the other in the cool sector (Fig. 9b). The prevalence of higher reports in the cool sector led to positive skewness, as portrayed by both the mean and median report distance lying in the cool sector. Therefore, although the modes for all three report types lie in the cool sector, it is important to consider the secondary mode in the warm sector. This may be a factor of storm motion from one sector to another, and this is one consideration that will be investigated further in this study.

Last, for supercells that interacted with warm fronts, there was no uniform preference for severe weather production in either the warm or cool sector (Fig. 9c). Although there were more hail reports in the cool sector and more tornado reports in the warm sector (Fig. 9c), the mode for both of these distributions lies in the warm sector. The more uniformly distributed hail reports led to both a mean and median closer to the boundary, whereas the more-strongly skewed tornado report distribution has its mode farther in the warm sector (Table 2). Again, it is worthwhile investigating whether this split in tornado and hail reports is due to supercell motion, which will be discussed in the next section. 
For all reports collected, those that are reported as significantly severe (tornado $\geq F / E F 2$, hail $\geq 2.00$ ", wind $\geq 75 \mathrm{mph}$ ) were analyzed separately to see if boundary proximity may play a role in more significant severe weather production. Because of the limited number of significantly severe reports in this study, only the mean and median will be analyzed (Table 1, Table 3). For all severe weather types occurring near outflow boundaries, the mean distance of the significantly severe reports was closer to the boundary than the overall mean distance of all reports (Fig. 9). For significant severe weather reports near stationary fronts and warm fronts, the mean and median distances are farther from the boundary; this may be a sampling issue due to the limited number of reports available for analysis. Overall, the result that significantly severe tornadoes and hail occur closer to the boundary, on average, than all severe weather is consistent with previous research, suggesting that boundaries can help enhance storms to produce significantly severe weather (e.g., Maddox et al. 1980; Markowski et al. 1998a; Rasmussen et al. 2000; Bunkers et al. 2006b; Weiss et al. 2015).

\section{c. Supercell motion}

The degree of interaction between a supercell and a nearby boundary is limited by the angle of supercell motion relative to the boundary (Atkins et al. 1999; Rasmussen et al. 2000; Bunkers et al. 2006b; Laflin and Houston 2012). As has been previously discussed, the longer a supercell spends in the proximity of a boundary, the more it is able to benefit from the locally enhanced environment on the meso- $\beta$ scale, thus leading to a stronger and more persistent mesocyclone (Atkins et al. 1999; Bunkers et al. 2006b). For each case included in this study, the average angle at which the supercell travels relative to the boundary throughout its lifetime was analyzed. These cases were then binned into smaller angles of interaction (less than or equal to $45^{\circ}$ ) and angles of interaction with a greater boundary-normal component of motion (greater than $45^{\circ}$ ). Overall, parent supercells with smaller interaction angles tended to produce tornado and hail reports closer to the boundary compared to supercells with larger interaction angles, with the exception of tornadoes near warm fronts (Fig. 10a-d). Wind reports showed no clear pattern or trend toward smaller interaction angles resulting in a narrower range of storm reports. Given that there are fewer wind reports overall, a larger sample is needed to be conclusive. It is also noteworthy that a majority of all severe weather report types (except for wind reports near warm fronts) for all three boundaries occurred with smaller angles of interaction (Table 4). For outflow boundaries, $78.7 \%$ of all tornado reports were observed with supercell-boundary motion within $45^{\circ}$; for stationary boundaries, smaller angles of interaction accounted for $63.6 \%$ of all tornado reports; and for warm front tornado reports, $59.2 \%$ of tornadoes were associated with smaller angles of interaction.

To support the claim that smaller interaction angles result in more time in the proximity of the boundary, the duration each supercell was within $70 \mathrm{~km}$ of each boundary type was compared to its angle of interaction with the boundary, as defined in the previous paragraph. Figure 11 portrays a scatterplot of each point with a linear line of best fit superposed on each scatterplot. For all three boundary types, it is shown that there is a general trend for supercells with smaller angles of interaction to spend more time in the vicinity of the boundary, as defined in this paper as within $70 \mathrm{~km}$ of the warm or cool sector (Fig. 11). Therefore, it can be concluded that the smaller interaction angles, combined with longer residence time of supercells in the vicinity of the boundary, have notable influence on supercell intensity and its ability to produce severe weather, due to the prolonged amount of time spent in the corridor of enhanced vertical vorticity, moisture convergence, and streamwise horizontal vorticity.

It also is prudent to examine how the angle of interaction between a supercell and surface boundary affects significantly severe weather; in this case, the differentiation of significantly severe tornadoes $(\geq F / E F$ 2 ) was compared between smaller angles of interaction $\left(\leq 45^{\circ}\right)$ and larger angles of interaction $\left(>45^{\circ}\right)$. Out of the 20 total significant tornado reports associated with outflow boundaries included in this study, 18 of them occurred with supercell-boundary angles less than $45^{\circ}$, whereas only two significant tornado reports occurred with angles greater than $45^{\circ}$ (Fig. 12a). For both stationary and warm fronts, a majority of both significant tornadoes and supercells that produced significant tornadoes were associated with smaller boundaryrelative angles (10 of 11 and 32 of 41, respectively) (Fig. 12b, c). The angle at which a supercell crosses or interacts with the boundary is shown here to play a role in severe weather production. Indeed, for smaller angles of interaction, a supercell is not only more likely to produce a tornado, but also to produce a significant tornado with a rating $\geq \mathrm{F} / \mathrm{EF} 2$. 
Table 3. Mean and median distances $(\mathrm{km})$ for significantly severe reports per boundary type. Negative distances represent the cool sector; positive distances represent the warm sector.

\begin{tabular}{|l|l|l|}
\hline & Mean $(\mathbf{k m})$ & Median $(\mathbf{k m})$ \\
\hline Tornado-outflow & 20.9 & 38.8 \\
\hline Hail-outflow & 15.4 & 19.9 \\
\hline Wind-outflow & -1.27 & -1.27 \\
\hline Tornado-stationary & -11.0 & -17.4 \\
\hline Hail-stationary & -4.7 & -17.4 \\
\hline Wind-stationary & -39.0 & -44.9 \\
\hline Tornado-warm & 21.1 & 24.9 \\
\hline Hail-warm & -20.4 & -36.7 \\
\hline Wind-warm & -52.6 & -52.6 \\
\hline
\end{tabular}

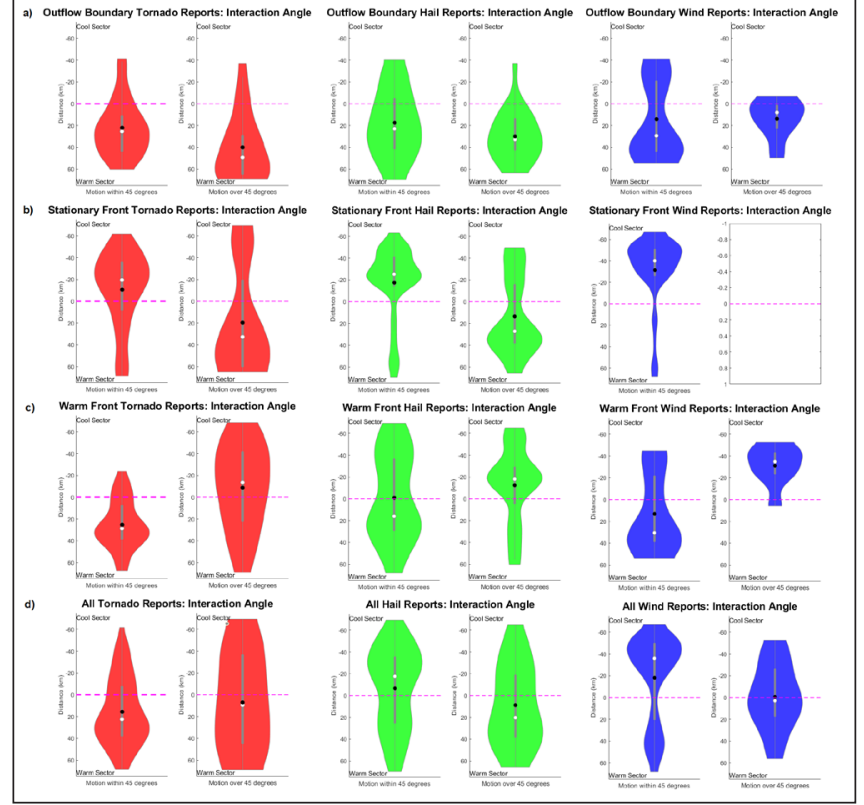

Figure 10. Violin plots of tornado (red) and hail (green) report distance distributions for all three boundary types divided by angle of interaction relative to the boundary, and for all reports combined, regardless of boundary type. Boundary-relative motion $\leq 45^{\circ}$ is on the left-hand side of each plot, and boundary-relative motion $>45^{\circ}$ is on the right-hand side. Boundary denoted by the magenta dashed line. The central dot marks the median, the thick gray line marks the inter-quartile range of the 25 th and 75 th percentiles, and the thin gray line is the range containing $95 \%$ of all data. The edges are a kernel density function of the distribution of data points, thus showing the distribution and frequency of reports rather than a traditional box plot. The black dot denotes the distribution mean. Analyzed distances $+/-10 \mathrm{~km}$. Note: There were no stationary front wind reports in cases with an angle $>45$ degrees.
To better differentiate severe weather production as a function of the direction of supercell motion, each report and boundary type was clustered based on whether the storm was moving toward the cool sector, toward the warm sector, or whether the storm motion remained within $20 \mathrm{~km}$ of its starting point with respect to the boundary's position throughout the supercell's lifetime. This was calculated by taking the distance of the storm from the boundary at the beginning of its lifetime and subtracting the distance of the storm at the end of its lifetime. This procedure followed the aforementioned convention of distance from the boundary in the cool sector defined as negative, whereas distance from the boundary in the warm sector is defined as positive. Therefore, a positive (negative) difference in the distance from a supercell to the boundary throughout its lifetime indicated that the storm was moving toward the cool (warm) sector. To account for smaller differences in overall storm distance from the boundary, a third category was chosen to represent the storm remaining within $20 \mathrm{~km}$ of its starting distance from the boundary throughout its lifetime, which will be labeled as "along boundary".

Figure 13 depicts the distribution of reports per boundary type within the three predefined subcategories of sector motion as violin plots. Although there are no clear trends with where the median or inter-quartile range of reports lie depending on the direction of a supercell's motion, it is noteworthy that the median values still remain within $40 \mathrm{~km}$ of a boundary, thus supporting the previous conclusion that this appears to be a favorable zone for severe weather production. Additionally, for all distributions except for hail occurring near a warm front and wind reports near a stationary front, a plurality of reports occur with supercells moving toward the cool sector (Table 5). The 
Table 4. Total number of severe reports per boundary type sorted by angle of interaction between the supercell and boundary.

\begin{tabular}{|l|l|l|}
\hline & Motion $<=\mathbf{4 5}$ degrees & Motion $>\mathbf{4 5}$ degrees \\
\hline Tornado-outflow & 59 & 16 \\
\hline Hail-outflow & 31 & 22 \\
\hline Wind-outflow & 16 & 13 \\
\hline Tornado-stationary & 42 & 24 \\
\hline Hail-stationary & 118 & 32 \\
\hline Wind-stationary & 59 & 0 \\
\hline Tornado-warm & 77 & 53 \\
\hline Hail-warm & 94 & 29 \\
\hline Wind-warm & 8 & 8 \\
\hline
\end{tabular}

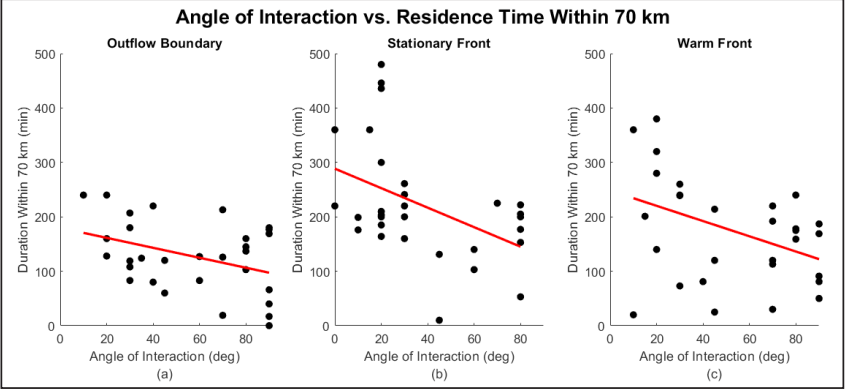

Figure 11. Scatterplot of angle of interaction between supercell and each boundary type versus the time each supercell spent within $70 \mathrm{~km}$ of the boundary in either the cool or warm sector. The red line is a line of best fit for each scatterplot, highlighting that on average, the lower the angle of interaction, the more time spent near the boundary.

proclivity of supercells to produce severe hail, strong winds, or a tornado while moving toward the cool sector makes physical sense, as just on the cool side of the boundary is where the largest temperature gradient (and associated baroclinic vorticity) lies, thus able to be tilted into the supercell. Despite previous research suggesting that boundary strength does not play a role in severe weather production beyond a certain value, with a dataset this large, it is worth investigating whether the temperature gradient may affect severe weather production on a more robust scale, as previous studies only considered one day, each (Atkins et al. 1999; Weiss et al. 2015).

\section{d. Temperature gradient}

It has been shown extensively that the presence of a boundary enhances nearby supercells, and therefore severe weather production. However, the gradient

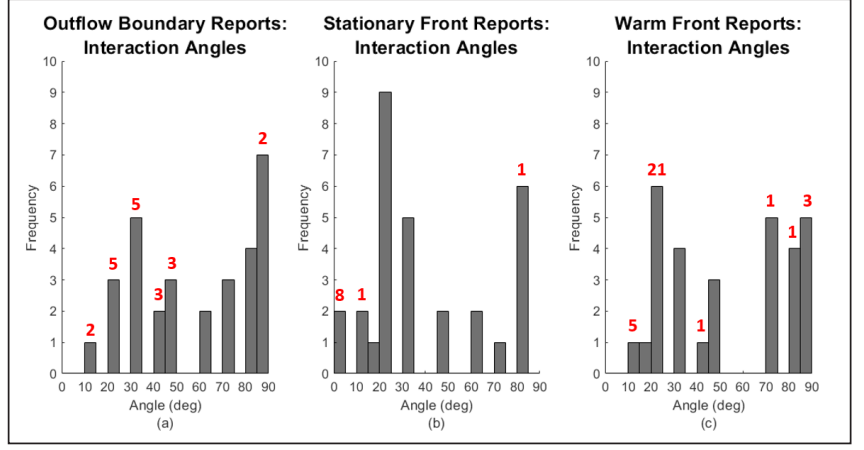

Figure 12. Histograms of the total number of cases per interaction angle for outflow (a), stationary (b), and warm fronts (c) in the black bars with frequency on the left y-axis, and the total number of significant tornadoes $(>$ F/EF2) in the bold red text above its corresponding angle range. Analyzed distances $+/-10 \mathrm{~km}$.

of that boundary has been shown to not affect the proclivity for tornadogenesis, nor rotation or increased updraft speed (Atkins et al. 1999; Weiss et al. 2015). Using the same reports analyzed in the distance distributions within $70 \mathrm{~km}$ of the boundary in the cool or warm sector, each report was also given a temperature gradient value at the time of severe weather production using ASOS archives. Sanders (1999) defined a strong temperature gradient as $8^{\circ} \mathrm{C}$ over $110 \mathrm{~km}$, or $0.073^{\circ} \mathrm{C} / \mathrm{km}$, whereas a gradient of $8^{\circ} \mathrm{C}$ over $220 \mathrm{~km}$, or $0.036^{\circ} \mathrm{C} / \mathrm{km}$, was defined as a moderate temperature gradient. In this study, the average temperature gradient was calculated as $0.064^{\circ} \mathrm{C} / \mathrm{km}$ over the lifetime of all 90 supercells; thus, the average temperature gradients analyzed herein are considered to be more strong than moderate (Fig. 14). Although the median value for temperature gradient associated with all three boundary types is nearly identical, it is noteworthy that outflow boundary temperature gradient distributions have 


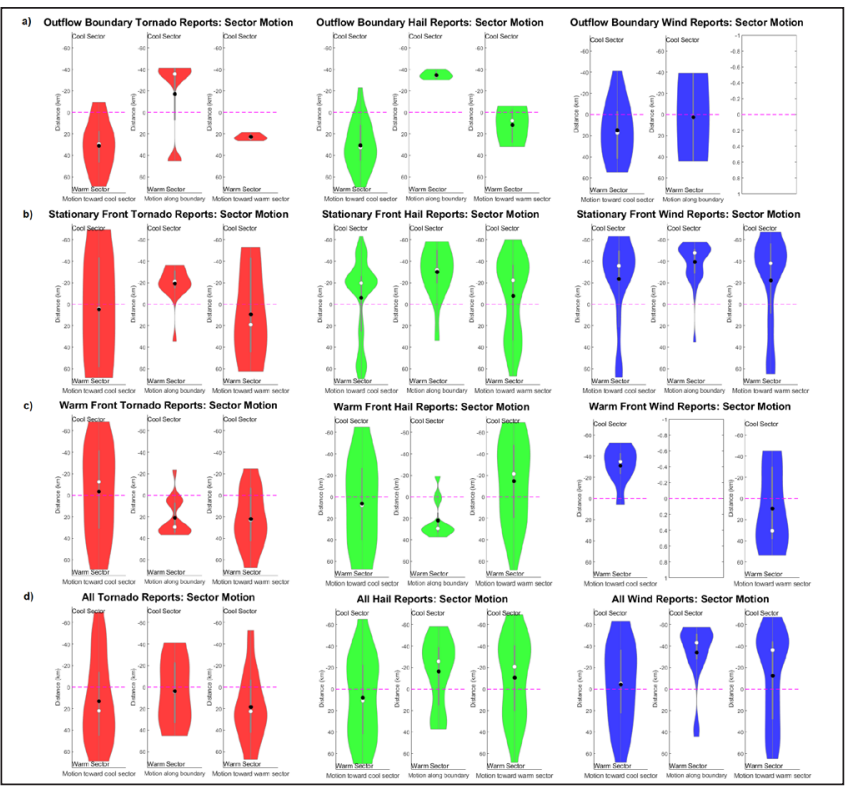

Figure 13. Violin plots of tornado and hail report distance separated by supercell motion over its lifetime either toward the cool sector (left), supercell motion within $20 \mathrm{~km}$ of the boundary throughout its lifetime (middle), and supercell motion over its lifetime toward the warm sector (right). Boundary denoted by the magenta dashed line. The central dot marks the median, the thick gray line marks the inter-quartile range of the 25th and 75th percentiles, and the thin gray line is the range containing $95 \%$ of all data. The edges are a kernel density function of the distribution of data points, thus showing the distribution and frequency of reports rather than a traditional box plot. The black dot denotes the distribution mean. Analyzed distances $+/-10 \mathrm{~km}$. Note: there were no wind reports associated with motion toward the warm sector for outflow interacting supercells, nor wind reports associated with motion along the boundary for warm front interacting supercells.

negative values (a result of cool and warm air locations switching) and are skewed in that direction, whereas warm front temperature gradient distributions have greater positive values, and therefore stronger analyzed temperature gradients. The temperature gradient of the surface boundaries may be influenced by the nocturnal transition, which cools the environmental air, therefore reducing the overall temperature gradient. This change is most noticeable in outflow boundaries, where the environmental air cooled to a temperature lower than the cold pool. Outflow boundaries are also more susceptible to lower temperature gradients, as most of the outflow boundary cases analyzed in this study occurred four hours later than warm and stationary fronts, as noted in Fig. 5. Because of this inherent influence of the nocturnal transition, it is expected that temperature gradients associated with severe weather production near outflow boundaries will be lesser than the temperature gradients analyzed over stationary or warm fronts.

Indeed, it is shown that the average temperature gradient for severe weather production near an outflow boundary is less than that for either stationary or warm fronts (Table 6). The proclivity for lesser temperature gradients in outflow boundary reports is also highlighted by the negative skewness associated with tornado and hail reports associated with outflow boundaries. Unlike the distance distributions seen in Fig. 9, the temperature gradient distributions are not bimodal (Fig. 15). Each report included in the temperature gradient analysis occurred within the $70 \mathrm{~km}$ restriction from the boundary. Therefore, it is subject to the same data availability errors, with nearly twice as many hail reports collected than tornado reports for both stationary and warm fronts. With the more unimodal appearance of these distributions, the mean and median temperature gradient value is much closer together than for report distance. It also is worth noting that for both stationary and warm fronts, the temperature gradient mode for tornado reports is stronger than the mode for severe hail or wind reports, except for the severe wind reports near warm fronts (Table 6).

Additionally, significantly severe reports superimposed on the severe report distributions highlights a relatively similar pattern for significantly severe weather production (Fig. 15). However, when analyzing the mean and median of the significantly severe distributions compared to the mean and median values of the generally severe distributions, it is shown that the significantly severe temperature gradient is larger for most of the distributions (Table 7). This highlights previous thinking that a stronger temperature gradient may produce stronger baroclinically generated horizontal vorticity, which can then be tilted into the nearby supercell and used to generate stronger rotation and updrafts, and therefore more significant severe weather. In order for the applications of this result to be more robust, we will test the statistical significance of how not only temperature gradients, but also distances relate to severe weather production, and whether boundary or report type can be used to highlight a different range of boundary strengths or distances for severe weather production. 
Table 5. Total number of severe reports per boundary type sorted by direction of motion of the supercell relative to the boundary throughout the supercell's lifetime.

\begin{tabular}{|l|l|l|l|}
\hline & Motion toward cool sector & $\begin{array}{l}\text { Motion difference within } \\
\mathbf{2 0} \mathbf{~ k m}\end{array}$ & Motion toward warm sector \\
\hline Tornado-outflow & 63 & 8 & 4 \\
\hline Hail-outflow & 43 & 5 & 5 \\
\hline Wind-outflow & 27 & 2 & 0 \\
\hline Tornado-stationary & 30 & 16 & 20 \\
\hline Hail-stationary & 63 & 27 & 60 \\
\hline Wind-stationary & 15 & 26 & 18 \\
\hline Tornado-warm & 54 & 31 & 45 \\
\hline Hail-warm & 44 & 12 & 67 \\
\hline Wind-warm & 8 & 1 & 7 \\
\hline
\end{tabular}

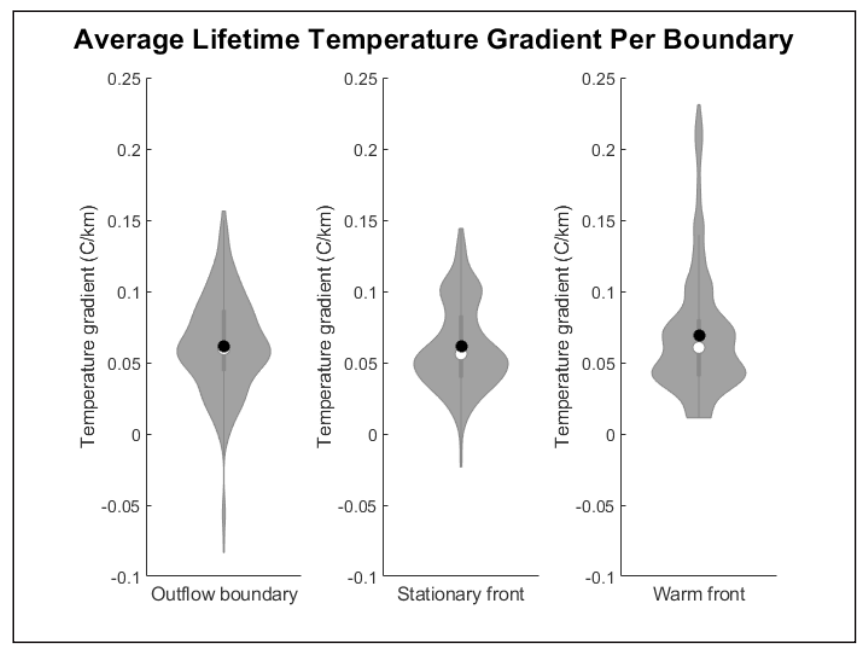

Figure 14. Violin plot of average temperature gradient of all supercells per (a) outflow boundary, (b) stationary front, and (c) warm front. The central dot marks the median, the thick gray line marks the inter-quartile range of the 25 th and 75 th percentiles, and the thin gray line is the range containing $95 \%$ of all data. The edges are a kernel density function of the distribution of data points, thus showing the distribution and frequency of reports rather than a traditional box plot. The black dot denotes the distribution mean. Negative temperature gradients are the result of the cool and warm air locations switching after the nocturnal transition.

\section{Statistical analyses}

Several differences were noted among the distributions of severe reports, both among report types and among boundary types. To identify whether these differences hold any significance, the two-way nonparametric Kolmogorov-Smirnov test (hereafter referred to as the KS test) was used to compare different pairs of distributions within the same report or boundary type. Ho for the KS test is that both test distributions could come from the same population distribution, whereas $\mathrm{H} 1$ is that both distributions cannot be subsets of the same population. Distributions will be compared to the standard $p$-value of 0.05 to determine significance. For results of the KS test to be reliable, a sample size of at least 30 is recommended; the wind reports from both outflow boundary and warm front cases only have 29 and 16 reports, respectively (Table 1). Thus, these distributions were removed from any statistical testing. Additionally, Edwards et al. (2018) highlighted the inherent error present in most severe wind reports; therefore, the stationary wind report distribution also will be omitted from testing for statistical significance. For brevity, Table 8 summarizes the statistically significant relationships among all of the examined comparisons, and these will be discussed in more detail in subsequent subsections. Interested readers may review the Appendix for a list of all statistical tests and their p-values.

\section{a. Boundary distance}

The core of this study was to assess the relationship between severe report generation and distance to nearby surface boundaries. Numerous distributions of severe reports were produced based on type of report and type of boundary within $70 \mathrm{~km}$ of the parent supercell. When comparing distances of tornado and hail reports within a given boundary type, the distributions tended to be similar for outflow and stationary boundaries; for example, outflow boundaries produce tornadoes and hail most frequently near $30 \mathrm{~km}$ in the warm sector 
Table 6. As in Table 2, but analyzed using temperature gradient distributions at the time of severe weather production, if the report was analyzed to be within $70 \mathrm{~km}$ of the boundary.

\begin{tabular}{|l|l|l|l|l|}
\hline Boundary Type: & Mean $\left({ }^{\circ} \mathrm{C} / \mathbf{k m}\right):$ & Median $\left({ }^{\circ} \mathrm{C} / \mathrm{km}\right):$ & Bin mode $\left({ }^{\circ} \mathrm{C} / \mathrm{km}\right):$ & Skewness: \\
\hline Tornado-outflow & 0.032 & 0.036 & $0.035-0.040$ & -1.12 \\
\hline Hail-outflow & 0.039 & 0.045 & $0.045-0.050$ & -1.47 \\
\hline Wind-outflow & 0.029 & 0.029 & $0.030-0.035$ & 0.46 \\
\hline Tornado-stationary & 0.032 & 0.027 & $0.060-0.065$ & 0.43 \\
\hline Hail-stationary & 0.042 & 0.039 & $0.025-0.030$ & 0.14 \\
\hline Wind-stationary & 0.043 & 0.039 & $0.040-0.045$ & 0.34 \\
\hline Tornado-warm & 0.037 & 0.036 & $0.040-0.045$ & 0.41 \\
\hline Hail-warm & 0.040 & 0.032 & $0.030-0.035$ & 0.43 \\
\hline Wind-warm & 0.040 & 0.041 & $0.040-0.045$ & -0.42 \\
\hline
\end{tabular}

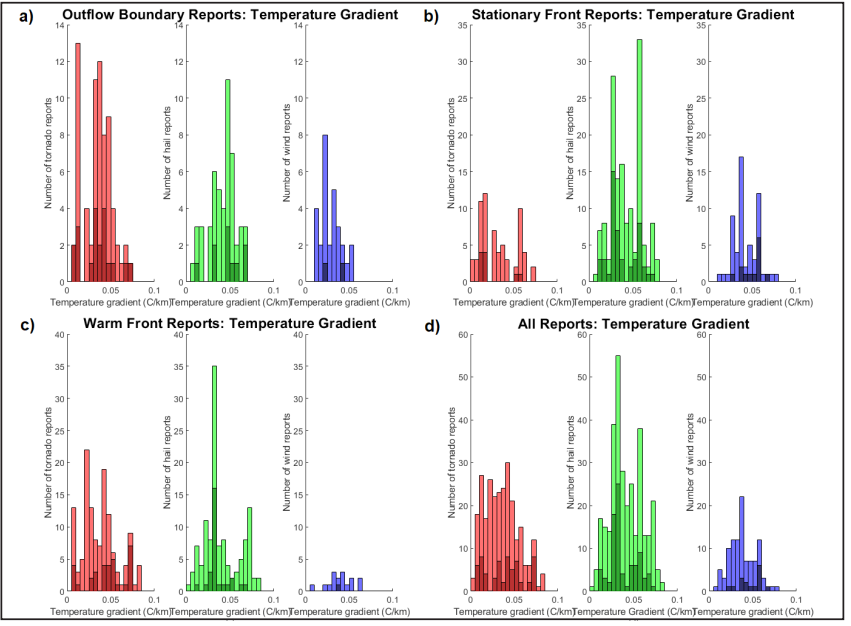

Figure 15. As in Fig. 9, for temperature gradient. Binned by $0.005^{\circ} \mathrm{C} / \mathrm{km}$.

(Table 8). Conversely, stationary boundaries produce severe weather most frequently near $25 \mathrm{~km}$ in the cool sector (Table 2; Table 8). Tornado and hail production by warm fronts, however, occurred at significantly different distances; tornadoes most frequently occurred farther in the warm sector than hail (Table 2; Table 8).

Within the same report type, all the comparisons were found to be statistically significant (Table 8). In other words, where tornadoes and hail tend to occur is sensitive to the boundary type. This may be a function of the different nature of outflow-supercell and stationary/ warm front-supercell interactions; nearly all supercells move toward the cool side of outflow boundaries and dissipate quickly once they reach the cool side (Table 5; Fig. 8a). On the other hand, supercells interacting with stationary and warm fronts are more evenly distributed in terms of moving away or toward the boundary (Table 5; Fig. $8 b-c)$. With this in mind, it is important to properly diagnose the boundary type. Although the method used in this paper is robust, it should be a priority of the meteorological community to develop or adopt more concrete definitions and analysis techniques, as this has been proven to significantly alter severe weather report distributions.

Because each distribution was found to be sensitive to boundary type, the distances used to discriminate between tornado and hail production for each boundary should be unique. These comparisons are summarized in Fig. 16, illustrating the ranges in which the majority of tornado and hail reports occurred, represented here by a range of distances encompassing one standard deviation on either side of the mean distance. For completeness, wind report distance ranges were also included, with the acknowledged limitation that those distances were not statistically tested. This figure demonstrates that, on average, the median distance at which tornado reports occur is closer to the boundary than the median distance at which hail reports occur for all boundary types, as verified by Table 2 . One possible influence on why distance distributions for boundaries were found to be statistically different is due to storm motion; both the angle of interaction and motion toward the warm or cool sector may also significantly influence report distances.

\section{b. Supercell motion}

Numerous studies have demonstrated that the angle at which a supercell interacts with a boundary affects not only its strength, but also its lifetime (Markowski et al. 1998a; Atkins et al. 1999; Bunkers et al. 2006b; Weiss et al. 2015). Accordingly, severe weather production should also be impacted. In the present study, we tested the significance of where tornado or hail reports were generated as classified by either small- 
Table 7. As in Table 3 for significantly severe reports, analyzed using temperature gradient distributions at the time of severe weather production, if the significantly severe report was analyzed to be within $70 \mathrm{~km}$ of the boundary.

\begin{tabular}{|l|l|l|}
\hline & Mean $\left({ }^{\circ} \mathbf{C} / \mathbf{k m}\right)$ & Median $\left({ }^{\circ} \mathbf{C} / \mathbf{k m}\right)$ \\
\hline Tornado-outflow & 0.035 & 0.037 \\
\hline Hail-outflow & 0.046 & 0.047 \\
\hline Wind-outflow & 0.034 & 0.034 \\
\hline Tornado-stationary & 0.023 & 0.016 \\
\hline Hail-stationary & 0.037 & 0.031 \\
\hline Wind-stationary & 0.050 & 0.056 \\
\hline Tornado-warm & 0.045 & 0.048 \\
\hline Hail-warm & 0.035 & 0.032 \\
\hline Wind-warm & 0.039 & 0.039 \\
\hline
\end{tabular}

angle $\left(\leq 45^{\circ}\right)$ or large-angle $\left(>45^{\circ}\right)$ boundary-relative motion. It should be noted that most severe weather occurred for supercells with small interaction angles, resulting in fewer than 30 data points for large-angle report distributions. As a result, these findings may not be as statistically robust.

Overall, the distances at which different types of severe weather in a given boundary type were generated tested as not sensitive to the boundary interaction angle; only supercells interacting at small angles with warm fronts produced tornadoes and hail at significantly different distances (Table 8). More significant differences arise when comparing different boundary types and angles of interaction for a given type of severe weather (Tables 9-10). For tornadoes, small interaction angles significantly reduced the distance from the boundary at which reports were generated compared to large interaction angles. Although these reports tended to occur in the warm sector, tornadoes associated with stationary fronts were significantly different from those associated with warm fronts or outflow boundaries, occurring more frequently in the cool sector. With large interaction angles, however, tornadoes associated with warm fronts were significantly different from those associated with stationary fronts or outflow boundaries, occurring more frequently in the cool sector. For hail reports, the supercell-boundary interaction angle resulted in significantly different locations of report generation for both stationary and warm fronts (Table 8 ), though the specific areas where reports tend to be found varied (Fig. 10b, c). Small interaction angles typically produced hail in the warm sector, though this was significantly different for stationary fronts. In contrast, with large interaction angles, hail is typically found in the warm sector, though the warm front distribution was significantly different.
Overall, it is clear that the angle at which the supercell interacts with the boundary demonstrates great skill in differentiating the distance at which severe weather will occur, with notable sensitivities across boundary types.

Most of the distributions produced in this study have a bimodal distribution of where severe weather is produced (Fig. 9), as discussed in the results section. It was suggested that this may be the influence of sector motion. Therefore, three different distributions were created: supercells traveling toward the cool sector, supercells that did not move more than $20 \mathrm{~km}$ from their originating distance from the boundary throughout their lifetime (along boundary), and supercells traveling toward the warm sector. This study then analyzed these distributions to see how they relate to one another, and whether there is any commonality between report type, boundary type, or a combination of both as it relates to sector motion. It should be noted that several of the along-boundary and toward-the-warm-sector distributions fail to meet the 30-report minimum criteria for robust statistical analysis, which is a limiting factor in the applicability of this analysis. Therefore, only statistical results of toward the cool sector comparisons will be presented in this subsection, with further statistical results included in Table 8 and the Appendix.

Comparisons of types of sector motion within a given boundary revealed that, on the whole, motion toward the cool sector produced severe weather at similar distances as motion toward the warm sector; only motion along a given boundary resulted in severe weather at significantly different locations (Fig. 13; Table 8). This result is notable in that it contradicts the previously stated hypothesis that sector motion may account for the bimodal appearance of many distance distributions (Fig. 9). Overall, a majority of the reports 
Table 8. Qualitative summary for the list of statistical comparisons between the two listed distributions and appropriate conclusions from the significantly different comparisons at the $5 \%$ confidence level. A p-value less than 0.05 means that there is less than a 5\% chance that the two distributions are from the same parent distribution, and is considered statistically significant.

\begin{tabular}{|c|c|}
\hline $\begin{array}{l}\text { I. Comparison of Distance from Boundary of Severe Report } \\
\text { Production }\end{array}$ & Nature of Significant Difference \\
\hline Warm front (tornado versus hail) & $\begin{array}{l}\text { Tornadoes and hail are produced at unique distances from warm } \\
\text { fronts }\end{array}$ \\
\hline Tornadoes (outflow boundary versus stationary front) & $\begin{array}{l}\text { Tornadoes occur closer to the boundary with stationary fronts than } \\
\text { outflow boundaries }\end{array}$ \\
\hline Tornadoes (outflow boundary versus warm front) & $\begin{array}{l}\text { Tornadoes occur closer to the boundary with warm fronts than } \\
\text { outflow boundaries }\end{array}$ \\
\hline Tornadoes (stationary versus warm front) & $\begin{array}{l}\text { Tornadoes occur closer to the boundary with stationary fronts than } \\
\text { warm fronts }\end{array}$ \\
\hline Hail (outflow boundary versus stationary front) & $\begin{array}{l}\text { Hail occurs closer to the boundary with stationary fronts than } \\
\text { outflow boundaries }\end{array}$ \\
\hline Hail (outflow boundary versus warm front) & $\begin{array}{l}\text { Hail occurs closer to the boundary with warm fronts than outflow } \\
\text { boundaries }\end{array}$ \\
\hline Hail (stationary versus warm front) & $\begin{array}{l}\text { Hail occurs closer to the boundary with warm fronts than stationary } \\
\text { fronts }\end{array}$ \\
\hline II. Comparison of Supercell-Boundary Interaction Angle & Nature of Significant Difference \\
\hline Warm front (tornado versus hail); less than $45^{\circ}$ & Hail is produced farther in the warm sector than tornadoes \\
\hline $\begin{array}{l}\text { Tornadoes (outflow boundary versus stationary front); less } \\
\text { than } 45^{\circ}\end{array}$ & $\begin{array}{l}\text { Tornadoes occur more in the warm sector near outflow boundaries } \\
\text { and in the cool sector near stationary fronts }\end{array}$ \\
\hline Tornadoes (stationary versus warm front); less than $45^{\circ}$ & $\begin{array}{l}\text { Tornadoes occur more in the warm sector near warm fronts and in } \\
\text { the cool sector near stationary fronts }\end{array}$ \\
\hline Hail (outflow boundary versus stationary front); less than $45^{\circ}$ & $\begin{array}{l}\text { Hail occurs more in the cool sector with stationary fronts and in the } \\
\text { warm sector near outflow boundaries }\end{array}$ \\
\hline Hail (stationary versus warm front); less than $45^{\circ}$ & $\begin{array}{l}\text { Hail occurs more often in the warm sector near stationary fronts } \\
\text { and more often near the boundary or in the cool sector near warm } \\
\text { fronts }\end{array}$ \\
\hline $\begin{array}{l}\text { Tornadoes (outflow boundary versus warm front); greater than } \\
45^{\circ}\end{array}$ & $\begin{array}{l}\text { Tornadoes occur more in the warm sector near outflow boundaries } \\
\text { and near the boundary near warm fronts }\end{array}$ \\
\hline Tornadoes (stationary versus warm front); greater than $45^{\circ}$ & $\begin{array}{l}\text { Tornadoes occur more in the warm sector near stationary fronts and } \\
\text { in the cool sector and near the boundary near warm fronts }\end{array}$ \\
\hline Hail (outflow boundary versus warm front); greater than $45^{\circ}$ & $\begin{array}{l}\text { Hail occurs more in the warm sector near outflow boundaries and } \\
\text { in the cool sector near warm fronts }\end{array}$ \\
\hline Hail (stationary versus warm front); greater than $45^{\circ}$ & $\begin{array}{l}\text { Hail occurs more in the warm sector near stationary fronts and in } \\
\text { the cool sector near warm fronts }\end{array}$ \\
\hline $\begin{array}{l}\text { Tornadoes, outflow boundaries (less than } 45^{\circ} \text { versus greater } \\
\text { than } 45^{\circ} \text { ) }\end{array}$ & $\begin{array}{l}\text { Smaller interaction angle results in tornadoes closer to boundary } \\
\text { (warm sector) }\end{array}$ \\
\hline $\begin{array}{l}\text { Tornadoes, stationary fronts (less than } 45^{\circ} \text { versus greater than } \\
45^{\circ} \text { ) }\end{array}$ & $\begin{array}{l}\text { Smaller interaction angle results in tornadoes closer to boundary } \\
\text { (cool sector) }\end{array}$ \\
\hline Tornadoes, warm fronts (less than $45^{\circ}$ versus greater than $45^{\circ}$ ) & Smaller interaction angle results in tornadoes in the warm sector \\
\hline Hail, stationary fronts (less than $45^{\circ}$ versus greater than $45^{\circ}$ ) & Smaller interaction angle results in hail in the cool sector \\
\hline Hail, warm fronts (less than $45^{\circ}$ versus greater than $45^{\circ}$ ) & Smaller interaction angle results in hail closer to the boundary \\
\hline
\end{tabular}


Table 8. (continued).

\begin{tabular}{|c|c|}
\hline III. Comparison of Supercell Sector Motion & Nature of Significant Difference \\
\hline Stationary front (tornado versus hail); toward cool sector & Tornadoes occur closer to the boundary than hail \\
\hline $\begin{array}{l}\text { Hail (outflow boundary versus stationary front); toward cool } \\
\text { sector }\end{array}$ & $\begin{array}{l}\text { Hail occurs in the cool sector near stationary fronts and in the } \\
\text { warm sector near outflow boundaries }\end{array}$ \\
\hline $\begin{array}{l}\text { Tornadoes (outflow boundary versus warm front); along } \\
\text { boundary }\end{array}$ & $\begin{array}{l}\text { Tornadoes occur more in the cool sector near outflow boundaries } \\
\text { and in the warm sector near warm fronts }\end{array}$ \\
\hline Tornadoes (stationary versus warm front); along boundary & $\begin{array}{l}\text { Tornadoes occur more in the cool sector near stationary fronts and } \\
\text { more in the warm sector near warm fronts }\end{array}$ \\
\hline Hail (outflow boundary versus warm front); along boundary & $\begin{array}{l}\text { Hail occurs more in the cool sector near outflow boundaries and in } \\
\text { the warm sector near warm fronts }\end{array}$ \\
\hline Hail (stationary versus warm front); along boundary & $\begin{array}{l}\text { Hail occurs more in the cool sector near stationary fronts and in the } \\
\text { warm sector near warm fronts }\end{array}$ \\
\hline $\begin{array}{l}\text { Tornadoes (outflow boundary versus stationary front); toward } \\
\text { warm sector }\end{array}$ & $\begin{array}{l}\text { Tornadoes occur closer to the boundary near stationary fronts and } \\
\text { more in the warm sector near outflow boundaries }\end{array}$ \\
\hline $\begin{array}{l}\text { Tornadoes (outflow boundary versus warm front); toward } \\
\text { warm sector }\end{array}$ & $\begin{array}{l}\text { Tornadoes occur more often in the warm sector near warm fronts } \\
\text { than near outflow boundaries }\end{array}$ \\
\hline $\begin{array}{l}\text { Hail (outflow boundary versus stationary front); toward warm } \\
\text { sector }\end{array}$ & $\begin{array}{l}\text { Hail occurs more in the warm sector near outflow boundaries and } \\
\text { in the cool sector near stationary fronts }\end{array}$ \\
\hline $\begin{array}{l}\text { Hail (outflow boundary versus warm front); toward warm } \\
\text { sector }\end{array}$ & $\begin{array}{l}\text { Hail occurs more in the warm sector near outflow boundaries and } \\
\text { in the cool sector near stationary fronts }\end{array}$ \\
\hline Hail (stationary versus warm front); toward warm sector & $\begin{array}{l}\text { Hail occurs more in the cool sector near stationary fronts than } \\
\text { warm fronts }\end{array}$ \\
\hline $\begin{array}{l}\text { Tornadoes (toward cool versus along boundary); outflow } \\
\text { boundary }\end{array}$ & $\begin{array}{l}\text { Storms moving along the boundary produce tornadoes closer to the } \\
\text { boundary }\end{array}$ \\
\hline $\begin{array}{l}\text { Tornadoes (toward warm versus along boundary); outflow } \\
\text { boundary }\end{array}$ & $\begin{array}{l}\text { Storms moving along the boundary produce tornadoes closer to the } \\
\text { boundary }\end{array}$ \\
\hline Hail (toward cool versus along boundary); outflow boundary & $\begin{array}{l}\text { Storms moving toward the cool sector produce more hail in the } \\
\text { warm sector }\end{array}$ \\
\hline Hail (toward warm versus along boundary); outflow boundary & $\begin{array}{l}\text { Storms moving toward the warm sector produce more hail in the } \\
\text { warm sector }\end{array}$ \\
\hline $\begin{array}{l}\text { Tornadoes (toward cool versus along boundary); stationary } \\
\text { front }\end{array}$ & $\begin{array}{l}\text { Storms moving toward the cool sector produce hail closer to the } \\
\text { boundary }\end{array}$ \\
\hline $\begin{array}{l}\text { Tornadoes (toward warm versus along boundary); stationary } \\
\text { front }\end{array}$ & $\begin{array}{l}\text { Storms moving toward the warm sector produce hail closer to the } \\
\text { boundary }\end{array}$ \\
\hline Hail (toward cool versus along boundary); stationary front & $\begin{array}{l}\text { Storms moving toward the cool sector produce hail closer to the } \\
\text { boundary }\end{array}$ \\
\hline Hail (toward warm versus along boundary); stationary front & $\begin{array}{l}\text { Storms moving toward the warm sector produce hail closer to the } \\
\text { boundary }\end{array}$ \\
\hline Tornadoes (toward cool versus warm); warm front & $\begin{array}{l}\text { Storms moving toward the cool sector produce tornadoes closer to } \\
\text { the boundary }\end{array}$ \\
\hline Tornadoes (toward cool versus along boundary); warm front & $\begin{array}{l}\text { Storms moving toward the cool sector produce tornadoes closer to } \\
\text { the boundary }\end{array}$ \\
\hline Tornadoes (toward warm versus along boundary); warm front & $\begin{array}{l}\text { Storms moving toward the warm sector produce more tornadoes in } \\
\text { the cool sector }\end{array}$ \\
\hline Hail (toward cool versus warm); warm front & $\begin{array}{l}\text { Storms moving toward the cool sector produce hail closer to the } \\
\text { boundary }\end{array}$ \\
\hline Hail (toward warm versus along boundary); warm front & $\begin{array}{l}\text { Storms moving toward the warm sector produce hail closer to the } \\
\text { boundary }\end{array}$ \\
\hline
\end{tabular}


Table 8. (continued).

\begin{tabular}{|l|l|}
\hline IV. Comparison of Boundary Temperature Gradients & Nature of Significant Difference \\
\hline Outflow boundaries (tornado versus hail) & Hail occurs with a stronger temperature gradient than tornadoes \\
\hline Stationary fronts (tornado versus hail) & Hail occurs with a stronger temperature gradient than tornadoes \\
\hline Tornadoes (outflow boundary versus stationary front) & $\begin{array}{l}\text { Tornadoes near outflow boundaries occur with a larger temperature } \\
\text { gradient }\end{array}$ \\
\hline Tornadoes (stationary versus warm front) & $\begin{array}{l}\text { Tornadoes near warm fronts occur with a larger temperature gradi- } \\
\text { ent }\end{array}$ \\
\hline Hail (outflow boundary versus warm front) & $\begin{array}{l}\text { Hail near outflow boundaries occur with a larger temperature } \\
\text { gradient }\end{array}$ \\
\hline
\end{tabular}

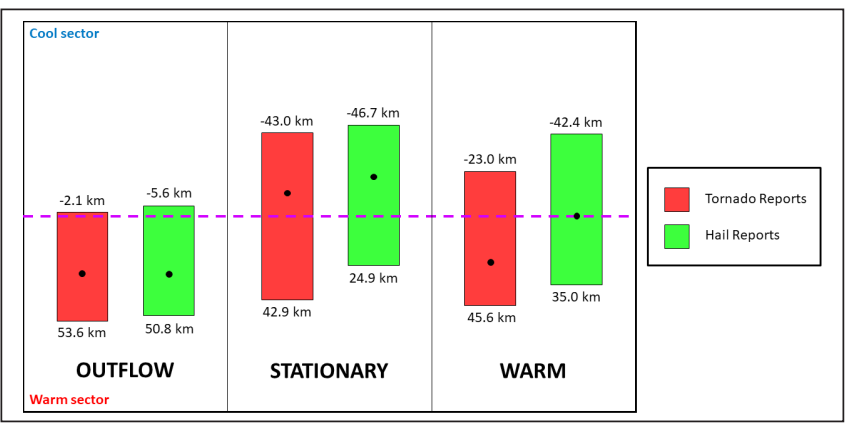

Figure 16. Visual representation of the distances that contain one standard deviation around the mean distance from the boundary (dashed magenta line) for each storm report type per boundary type $(+/-10$ $\mathrm{km})$. Negative distances indicate distance is in the cool sector, positive distances are the warm sector. Black dot represents median of the distribution.

occur in supercell motions toward the cool sector, regardless of boundary or report type, which suggests that supercells traveling toward cooler air show a greater propensity for severe weather production.

\section{c. Temperature gradient}

Last, this study investigated the influence of boundary strength on severe weather production. For temperature gradient distributions, the comparison of different report types within a boundary type showed that tornado and hail production occur at statistically different magnitudes, except in warm fronts (Table 8); specifically, tornadoes tend to be more frequent when the boundary strength is weaker (Tables 7-8). Indeed, tornadoes generated near stationary fronts occur at significantly smaller temperature gradients compared to tornadoes near warm fronts or outflow boundaries (Table 8). Physically, tornadoes require baroclinically generated streamwise vorticity (e.g., Davies-Jones and Brooks 1993; Markowski et al. 2002; Dahl et al.
2014), which can be augmented by the presence of surface boundaries (e.g., Markowski et al. 1998a). However, too much cold air (as implied by a stronger temperature gradient) could stabilize the low-level environment and reduce the potential for stretching vorticity into the vertical (e.g., Nowotarski et al. 2011; Weiss et al. 2015; Nowotarski and Markowski 2016). Although hail production is typically not associated with surface boundaries, such a feature could provide enhanced convergence and may strengthen updrafts, thus encouraging hail production. More detailed examinations of spatial variations in environmental parameters near boundaries and production of severe weather are left for future work.

\section{Discussion and conclusions}

It has been well-established that surface boundaries lead to enhanced convection and severe weather. This has been primarily understood in the context of enhancing tornadogenesis due to the increased helicity and baroclinically generated horizontal vorticity increasing low-level rotation (e.g., Maddox et al. 1980; Markowski et al. 1998a; Wakimoto et al. 1998; Atkins et al. 1999), though the extent to which other types of severe weather can be enhanced by the presence of a boundary had yet to be established. This study measured the distance at which over 600 severe reports occurred for 90 supercells interacting with outflow boundaries, stationary fronts, and warm fronts, with 30 storms for each boundary. These report distributions for each report and boundary type were further refined by angle of interaction and sector motion to determine the extent to which those factors may have an influence. Additionally, the influence of temperature gradient strength on severe weather production was studied.

This study concluded that on average, the distance at which tornado reports occur is closer to the boundary than hail or wind reports. Additionally, statistical testing 
confirmed that both report and boundary type play a role in differentiating the distance at which severe weather occurs. Accordingly, Fig. 16 shows a range of distances at which a majority of reports occur, as well as where the median distance is per distribution. This figure is meant to provide forecasters with an additional layer to assist with situational awareness in situations with multiple supercells in otherwise unfavorable environments. As demonstrated in previous cases, the local environment near a boundary can be favorable for not only supercells to develop, but for severe weather production and tornadogenesis to occur. In an operational environment, results from this study as presented in Fig. 16 can be utilized to provide enhanced mesoanalysis, such as highlighting favorable zones on either side of the boundary for severe weather to occur if convective initiation is happening across a broad zone. This study may also heighten the forecaster's awareness if a remnant outflow boundary or front progresses through their forecast area in an otherwise unfavorable environment for severe weather, resultantly raising concern that severe weather may be possible.

Reports were further refined by angle of interaction with the boundary, as well as sector motion. It was found that a majority of reports occurred with smaller interaction angles (less than or equal to $45^{\circ}$ ) and storms moving toward the cool sector, or further into the cool sector. Both of these make physical sense, as a smaller interaction angle between a supercell and a boundary means that the parent supercell spends a longer amount of time in the favorable environment near a boundary, and is therefore able to have a longer lifetime and produce more severe weather (as evidenced in Fig. 11). Additionally, a majority of significant tornadoes $(>\mathrm{F} /$ EF2) occur with smaller angles of interaction between the parent supercell and nearby boundary. A greater number of severe reports occurring with supercells traveling toward the cool sector also makes physical sense, as the definition of a boundary puts the stronger temperature gradient immediately on the cool side of the boundary. As previously demonstrated in this study, both temperature gradient and distance to the boundary play a role in severe weather production; therefore, as a supercell travels closer to that zone of stronger baroclinically generated horizontal vorticity, it is expected that supercell strength will increase, and therefore, so will severe weather production.

For both warm and stationary fronts, the temperature gradient mode associated with tornado reports is weaker than the one for hail reports, suggesting that tornadoes, while benefiting from baroclinically generated horizontal vorticity near boundaries, are not favored when there is too much cold, stable air. A more meso- $\gamma$ examination of temperature perturbations at the surface and aloft may provide additional insight into the observed pattern of tornadoes occurring with a weaker temperature gradient than severe hail. The average temperature gradient for significantly severe reports (tornado $\geq \mathrm{F} / \mathrm{EF} 2$, hail $\geq 2.00$ ", wind $\geq 75 \mathrm{mph}$ ) was larger than overall temperature gradient distributions for the same report and boundary type. This indicates that a stronger temperature gradient, likely without excessive convective inhibition, is associated with increased horizontal vorticity available to ingest into a supercell, thus able to create a stronger and more persistent updraft, leading to more significantly severe weather.

A more in-depth analysis about the background environment surrounding the supercells would further support the conclusion that supercells present near a boundary can overcome unfavorable environments, as proven earlier in the 25 May 2016 case study, rather than severe weather that would have formed in the warm sector, regardless of boundary presence. This is an acknowledged limitation of this study, and one that should be investigated further in future observational studies and/or numerical simulations. Future numerical simulations investigating the distance of supercell boundary interactions should test various distances of a simulated supercell from a boundary, as well as varying the boundary strength and supercell motion, to help clarify the applicability of this observational study in an idealized simulation.

Acknowledgments: We are thankful for the input and guidance from Dr. Matt Eastin and Terry Shirley from UNC Charlotte. Additionally, the support and insightful conversations with the Severe Storms Research Group (Matthew Gropp and Cody Ledbetter) helped inspire many facets of this study. Thank you to Jennifer Laflin, Randy Bowers, and one anonymous reviewer whose insightful comments helped with the development of this manuscript. 


\section{APPENDIX}

\section{KS test statistical results}

List of temperature gradient distribution comparisons and associated p-values from the Two-Way KS Test. A p-value less than 0.05 means that there is less than a $5 \%$ chance that the two distributions are from the same parent distribution, and is considered statistically significant; these values are italicized below. The analyses included below are the distributions of distance from the boundary; small and large angles of motion of the supercell relative to the boundary; whether the supercell moves toward the cool sector, toward the warm sector, or along the boundary throughout its lifetime; and comparisons of temperature gradient distributions per boundary and report type.

\begin{tabular}{|l|l|l|l|l|l|l|l|}
\hline I. Comparison of Different Report Types \\
\hline Distribution Comparison & \multicolumn{1}{|c|}{ Distance } & \multicolumn{2}{|c|}{ Angle Motion } & \multicolumn{3}{c|}{ Sector Motion } & \multicolumn{1}{c|}{$\begin{array}{l}\text { Temp. } \\
\text { Grad. }\end{array}$} \\
\hline & & $\begin{array}{l}\text { Less than } \\
\mathbf{4 5}\end{array}$ & $\begin{array}{l}\text { Greater } \\
\text { than 45 }\end{array}$ & $\begin{array}{l}\text { Toward } \\
\text { Cool }\end{array}$ & Along & $\begin{array}{l}\text { Toward } \\
\text { Warm }\end{array}$ & \\
\hline $\begin{array}{l}\text { Tornado-Outflow and } \\
\text { Hail-Outflow }\end{array}$ & 0.749 & 0.368 & 0.065 & 0.259 & 0.667 & 0.958 & 0.028 \\
\hline $\begin{array}{l}\text { Tornado-Stationary and } \\
\text { Hail-Stationary }\end{array}$ & 0.059 & 0.214 & 0.699 & $5.580 \mathrm{e}-07$ & 0.886 & 0.184 & $2.196 \mathrm{e}-05$ \\
\hline $\begin{array}{l}\text { Tornado-Warm and Hail- } \\
\text { Warm }\end{array}$ & $6.82 \mathrm{e}-04$ & $8.947 \mathrm{e}-06$ & 0.090 & 0.055 & 0.051 & 0.183 & 0.087 \\
\hline
\end{tabular}

\begin{tabular}{|l|l|l|l|l|l|l|l|}
\hline II. Comparison of Different Boundary Types & \multicolumn{1}{|c|}{ Angle Motion } & \multicolumn{3}{c|}{ Sector Motion } & \multicolumn{1}{c|}{$\begin{array}{l}\text { Temp. } \\
\text { Grad. }\end{array}$} \\
\hline Distribution Comparison & Distance & \multicolumn{2}{|c|}{$\begin{array}{l}\text { Less than } \\
\mathbf{4 5}^{\circ}\end{array}$} & $\begin{array}{l}\text { Greater } \\
\text { than 45 }\end{array}$ & $\begin{array}{l}\text { Toward } \\
\text { Cool }\end{array}$ & Along & Warm \\
\hline $\begin{array}{l}\text { Tornado-Outflow and } \\
\text { Tornado-Stationary }\end{array}$ & $6.688 \mathrm{e}-07$ & $1.063 \mathrm{e}-08$ & 0.102 & 0.415 & 0.093 & $1.421 \mathrm{e}-07$ & 0.0302 \\
\hline $\begin{array}{l}\text { Tornado-Outflow and } \\
\text { Tornado-Warm }\end{array}$ & 0.013 & 0.464 & $2.045 \mathrm{e}-04$ & 0.267 & $5.996 \mathrm{e}-04$ & $1.609 \mathrm{e}-04$ & 0.195 \\
\hline $\begin{array}{l}\text { Tornado-Stationary and } \\
\text { Tornado-Warm }\end{array}$ & 0.001 & $3.610 \mathrm{e}-10$ & 0.0016 & 0.135 & $4.344 \mathrm{e}-08$ & 0.244 \\
\hline $\begin{array}{l}\text { Hail-Outflow and } \\
\text { Hail-Stationary }\end{array}$ & $3.725 \mathrm{e}-12$ & $7.278 \mathrm{e}-09$ & 0.161 & 0.033 & 0.383 & $7.755 \mathrm{e}-04$ \\
\hline $\begin{array}{l}\text { Hail-Outflow and Hail- } \\
\text { Warm }\end{array}$ & $7.017 \mathrm{e}-05$ & 0.0805 & $1.960 \mathrm{e}-06$ & 0.051 & $4.217 \mathrm{e}-04$ & $3.775 \mathrm{e}-04$ & 0.034 \\
\hline $\begin{array}{l}\text { Hail-Stationary and Hail- } \\
\text { Warm }\end{array}$ & 0.004 & $3.215 \mathrm{e}-07$ & 0.007 & 0.075 & $3.984 \mathrm{e}-06$ & 0.027 \\
\hline
\end{tabular}

Comparisons using the Two-Way KS test analyzing distributions of the same report and boundary type, but with different angles of motion and sectors of motion. P-values less than 0.05 are considered statistically significant, and are italicized below.

\begin{tabular}{|l|l|l|}
\hline I. Comparison of Different Angles of Motion & Distribution 2 & P-Value \\
\hline Distribution 1 & Tornado-Outflow, greater than $45^{\circ}$ & 0.0052 \\
\hline Tornado-Outflow, less than $\mathbf{4 5}^{\mathbf{0}}$ & 0.234 \\
\hline Hail-Outflow, less than $\mathbf{4 5}^{\mathbf{0}}$ & Hail-Outflow, greater than $45^{\circ}$ & $1.584 \mathrm{e}-04$ \\
\hline Tornado-Stationary, less than $\mathbf{4 5}^{\mathbf{0}}$ & Tornado-Stationary, greater than 45 & $3.612 \mathrm{e}-06$ \\
\hline Hail-Stationary, less than $\mathbf{4 5}^{\mathbf{0}}$ & Hail-Stationary, greater than $45^{\circ}$ & $5.383 \mathrm{e}-08$ \\
\hline Tornado-Warm, less than $\mathbf{4 5}^{\mathbf{0}}$ & Tornado-Warm, greater than $45^{\circ}$ & 0.021 \\
\hline Hail-Warm, less than $\mathbf{4 5}^{\mathbf{0}}$ & Hail-Warm, greater than $45^{\circ}$ & \\
\hline
\end{tabular}


APPENDIX (continued)

\begin{tabular}{|c|c|c|}
\hline Distribution 1 & Distribution 2 & P-Value \\
\hline Tornado-Outflow, toward cool sector & Tornado-Outflow, toward warm sector & 0.107 \\
\hline Tornado-Outflow, toward cool sector & Tornado-Outflow, along the boundary & $2.513 \mathrm{e}-04$ \\
\hline Tornado-Outflow, toward warm sector & Tornado-Outflow, along the boundary & 0.0481 \\
\hline Hail-Outflow, toward cool sector & Hail-Outflow, toward warm sector & 0.077 \\
\hline Hail-Outflow, toward cool sector & Hail-Outflow, along the boundary & $5.656 \mathrm{e}-05$ \\
\hline Hail-Outflow, toward warm sector & Hail-Outflow, along the boundary & 0.004 \\
\hline Tornado-Stationary, toward cool sector & Tornado-Stationary, toward warm sector & 0.672 \\
\hline Tornado-Stationary, toward cool sector & Tornado-Stationary, along the boundary & 0.013 \\
\hline Tornado-Stationary, toward warm sector & Tornado-Stationary, along the boundary & $6.673 \mathrm{e}-04$ \\
\hline Hail-Stationary, toward cool sector & Hail-Stationary, toward warm sector & 0.072 \\
\hline Hail-Stationary, toward cool sector & Hail-Stationary, along the boundary & 0.003 \\
\hline Hail-Stationary, toward warm sector & Hail-Stationary, along the boundary & 0.045 \\
\hline Tornado-Warm, toward cool sector & Tornado-Warm, toward warm sector & $4.951 \mathrm{e}-05$ \\
\hline Tornado-Warm, toward cool sector & Tornado-Warm, along the boundary & $1.692 \mathrm{e}-04$ \\
\hline Tornado-Warm, toward warm sector & Tornado-Warm, along the boundary & 0.007 \\
\hline Hail-Warm, toward cool sector & Hail-Warm, toward warm sector & 0.009 \\
\hline Hail-Warm, toward cool sector & Hail-Warm, along the boundary & 0.079 \\
\hline Hail-Warm, toward warm sector & Hail-Warm, along the boundary & $2.736 \mathrm{e}-04$ \\
\hline
\end{tabular}

\section{REFERENCES}

Atkins, N. T., M. L. Weisman, and L. J. Wicker, 1999: The influence of preexisting boundaries on supercell evolution. Mon. Wea. Rev., 127, 2910-2927, CrossRef.

Blair, S. F., and Coauthors, 2017: High-Resolution hail observations: Implications for NWS warning operations. Wea. Forecating, 32, 1101-1119, CrossRef.

Boustead, J. M., B. E Mayes, W. Gargan, J. L. Leighton, G. Phillips, and P. N. Schumacher, 2013: Discriminating environmental conditions for significant warm sector and boundary tornadoes in parts of the Great Plains. Wea. Forecasting, 28, 1498-1523, CrossRef.

Bunkers, M. J., M. R. Hjelmfelt, and P. L. Smith, 2006a: An observational examination of long-lived supercells. Part I: Characteristics, evolution, and demise. Wea. Forecasting, 21, 673-688, CrossRef.

, J. S. Johnson, L. J. Czepyha, J. M. Grzywacz, B. A. Klimowski, and M. R. Hjelmfelt, 2006b: An observational examination of long-lived supercells. Part II: environmental conditions and forecasting. Wea. Forecasting, 21, 689-714, CrossRef.

Dahl, J. M. L., M. D. Parker, and L. J. Wicker, 2014: Imported and storm-generated near-ground vertical vorticity in a simulated supercell. J. Atmos. Sci., 71, 3027-3051, CrossRef.
Davies-Jones, R.P., and H.E. Brooks, 1993: Mesocyclogenesis from a theoretical perspective. The tornado: its structure, dynamics, prediction, and hazards. Geophys. Monogr. Amer. Geophys. Union, 79, 105-114, CrossRef.

Doswell, C. A. III, H. E. Brooks, and M. P. Kay, 2005: Climatological estimates of daily local nontornadic severe thunderstorm probability for the United States. Wea. Forecating, 20, 577-595, CrossRef.

Edwards, R., J. T. Allen, and G. W. Carbin, 2018: Reliability and climatological impacts of convective wind estimations. J. Appl. Meteor. Climatol., 57, 1825-1845, CrossRef.

Fawbush, E. J., and R. C. Miller, 1953: A method for forecasting hailstone size at the Earth's surface. Bull. Amer. Meteor. Soc., 34, 235-244, CrossRef.

Fierro, A. O., M. S. Gilmore, E. R. Mansell, L. J. Wicker, and J. M. Straka, 2006: Electrification and lightning in an idealized boundary-crossing supercell simulation of 2 June 1995. Mon. Wea. Rev., 134, 3149-3172, CrossRef.

Gagne II, D. J., A. McGovern, J. B. Basara, R. A. Brown, 2012: Tornadic supercell environments analyzed using surface and reanalysis data: A spatiotemporal relational data-mining approach. J. Appl. Meteor. Climatol., 51, 2203-2217, CrossRef. 
Gilmore, M. S. and L. J. Wicker, 2002: Influences of the local environment on supercell cloud-to-ground lightning, radar characteristics, and severe weather on 2 June 1995. Mon. Wea. Rev., 130, 2349-2372, CrossRef.

Houston, A. L. and R. B. Wilhelmson, 2012: The impact of airmass boundaries on the propagation of deep convection: A modeling-based study in a high-CAPE, low-shear environment. Mon. Wea. Rev., 140, 167-183, CrossRef.

Laflin, J. M. and A. L. Houston, 2012: A modeling study of supercell development in the presence of a preexisting airmass boundary. Electronic J. Severe Storms Meteor., 7, 1-29, CrossRef.

Maddox, R. A., L. R. Hoxit, and C. F. Chappell, 1980: A study of tornadic thunderstorm interactions with thermal boundaries. Mon. Wea. Rev., 108, 322-336, CrossRef.

Markowski, P. M., E. N. Rasmussen, and J. M. Straka, 1998a: The occurrence of tornadoes in supercells interacting with boundaries during VORTEX-95. Wea. Forecasting, 13, 852-859, CrossRef. , J. M. Straka, E. N. Rasmussen, and D. O. Blanchard, 1998b: Variability of storm-relative helicity during VORTEX. Mon. Wea. Rev., 126, 2959-2971, CrossRef. , and _ 2002: Direct surface thermodynamic observations within the rear-flank downdrafts of nontornadic and tornadic supercells. Mon. Wea. Rev., 130, 1692-1721, CrossRef.

Nowotarski, C. J., P. M. Markowski, and Y. P. Richardson, 2011: The characteristics of numerically simulated supercell storms situated over statically stable boundary layers. Mon. Wea. Rev., 139, 3139-3162, CrossRef. and _ 2016: Modifications to the near-storm environment induced by simulated supercell thunderstorms. Mon. Wea. Rev., 144, 273-293, CrossRef.

Rasmussen, E.N., J. M. Straka, R. Davies-Jones, C. A. Doswell, F. H. Carr, M. D. Eilts, and D. R. MacGorman, 1994: Verification of the Origins of Rotation in Tornadoes Experiment: VORTEX. Bull. Amer. Meteor. Soc., 75, 995-1006, CrossRef.

, E. N., S. Richardson, J. M. Straka, P. M. Markowski, and D. O. Blanchard, 2000: The association of significant tornadoes with a baroclinic boundary on 2 June 1995. Mon. Wea. Rev., 128, 174-191, CrossRef.

Sanders, F., 1999: A proposed method of surface map analysis. Mon. Wea. Rev., 127, 945-955, CrossRef.

Stumpf, G. J., A. Witt, E. D. Mitchell, P. L. Spencer, J. T. Johnson, M. D. Eilts, K. W. Thomas, and D. W. Burgess, 1998: The National Severe Storms Laboratory mesocyclone detection algorithm for the WSR-88D. Wea. Forecasting, 13, 304-326, CrossRef.

Thompson, R. L., C. M. Mead, and R. Edwards, 2007: Effective storm-relative helicity and bulk shear in supercell thunderstorm environments. Wea. Forecasting, 22, 102-115, CrossRef.
Trapp, R. J., D. M. Wheatley, N. T. Atkins, R. W. Przybylinski, and R. Wolf, 2006: Buyer beware: Some words of caution on the use of severe wind reports in post-event assessment and research. Wea. Forecasting, 21, 408-415, CrossRef.

Wakimoto, R. M., C. Liu, and H. Cai, 1998: The Garden City, Kansas storm during VORTEX 95. Part I: Overview of the storm's life cycle and mesocyclogenesis. Mon. Wea. Rev., 126, 372-392, CrossRef.

Weiss, S. J., J. A. Hart, and P. R. Janish, 2002: An examination of severe thunderstorm wind report climatology: 1970-1999. Preprints, 21st Conf. Severe Local Storms, San Antonio, TX, Amer. Meteor. Soc., 446-449, CrossRef.

Weiss, C. C., D. C. Dowell, J. L. Schroeder, P. S. Skinner, A. E. Reinhart, P. M. Markowski, and Y. P. Richardson, 2015: A comparison of near-surface buoyancy and baroclinity across three VORTEX2 supercell intercepts. Mon. Wea. Rev., 143, 2736-2753, CrossRef. 